\title{
Interocular Suppression in the Visual Cortex of Strabismic Cats
}

\author{
Frank Sengpiel, ${ }^{1}$ Colin Blakemore, ${ }^{1}$ Peter C. Kind, ${ }^{1, a}$ and RIchard Harrad ${ }^{2}$ \\ 'University Laboratory of Physiology, University of Oxford, Oxford OX1 3PT, United Kingdom and 'Bristol Eye Hospital, \\ Bristol BS1 2LX, United Kingdom
}

\begin{abstract}
Strabismic humans usually experience powerful suppression of vision in the nonfixating eye. In an attempt to demonstrate physiological correlates of such suppression, we recorded from the primary visual cortex of cats with surgically induced squint and studied the responses of neurons to drifting gratings of different orientation, spatial frequency, and contrast in the two eyes. Only 1 of 50 apparently monocular cells showed any evidence of remaining, subliminal excitatory input from the "silent" eye when the two eyes were stimulated with gratings of similar orientation, and even among the small proportion of cells that remained binocularly driven, very few exhibited facilitation when stimulated binocularly. The majority of cells from both exotropes and esotropes, even those that could be independently driven through either eye, displayed nonspecific interocular suppression: stimulation of the nondominant eye with a drifting grating of any orientation depressed the response to an optimal grating being presented to the dominant eye. This phenomenon exhibited a gross nonlinearity in that it was dependent on the temporal sequence of stimulus presentation: stimulation of the nondominant eye caused significant suppression only if the neuron was already responding to an appropriate stimulus in the dominant eye, but not when onset of stimulation in the two eyes was simultaneous. Interocular suppression was always independent of the relative spatial phase of the two grating stimuli, and usually broadly tuned for the spatial frequency of the suppressive stimulus. Suppression may depend on inhibitory interaction between neighboring ocular dominance columns, combined with the loss of conventional disparity-selective binocular interactions for matched stimuli in the two eyes. The similarity of interocular suppression in strabismic cats and that caused by orthogonal gratings in the two eyes in normal cats (Sengpiel and Blakemore, 1994; Sengpiel et al., 1994) suggests that strabismic suppression and binocular rivalry depend on similar neural mechanisms.

IKey words: strabismus, interocular suppression, binocular rivalry, contrast gain control, striate cortex, cat]
\end{abstract}

\footnotetext{
received Mar. 2, 1994; revised May 2, 1994; accepted May 11, 1994

This research was supported by a programme grant (PG7900491) from the Medical Research Council. F.S. held the Michael Foster Scholarship at Linacre College, Oxford (1990-1992), and a studentship from the Oxford McDonnell-Pew Centre for Cognitive Neuroscience (1992-1993). We are grateful to Cambridge Electronic Design, Ltd. for cooperating in the development of the visUAL sTIMULATION (vs) software package.

Correspondence should be addressed to Colin Blakemore, University Laboratory of Physiology, Parks Road, Oxford OX1 3PT, UK.

'Present address: Section of Neurobiology, Yale University School of Medicine New Haven, CT 06510.

Copyright (C) 1994 Society for Neuroscience $0270-6474 / 94 / 146855-17 \$ 05.00 / 0$
}

Strabismus, or misalignment of the visual axes of the two eyes, is a common visual disorder in humans and also in monkeys reared in captivity (Kiorpes and Boothe, 1981). Most humans who develop strabismus at an early age do not complain of obvious double vision (diplopia) despite the fact that the images of each feature in the visual scene fall on geometrically noncorresponding points in the two retinas. In rare cases, single vision in strabismus is attributed to the phenomenon of harmonious anomalous retinal correspondence (ARC), in which functional correspondence is shifted to match the angle of squint. The two images of an object give rise to a single sensation of visual direction despite the misalignment of the eyes, and there is even rudimentary stereoscopic vision (for review, see Schor, 1991). Much more commonly, double vision is obviated through partial or global suppression of information from one eye.

In the past 30 years much has been learned about the anomalies of binocular vision associated with strabismus, from both psychophysical and neurophysiological studies. Since the pioneering work of Hubel and Wiesel (1965), artificially induced strabismus has been widely investigated and has provided an increasingly convincing animal model of certain kinds of human squint. Different forms of experimental strabismus, including surgically induced and optically induced squint, have yielded a variety of results with respect to the responses of neurons in the primary visual pathway, prevailing fixation patterns, and the occurrence of reduced acuity through the squinting eye (strabismic amblyopia) (for review, see Mitchell, 1988). There is general agreement that strabismus, whether convergent (esotropia) or divergent (exotropia), leads to a marked reduction in the proportion of neurons in the primary visual cortex that are directly excitable through either eye (e.g., Hubel and Wiesel, 1965; Yinon et al., 1975; Blakemore, 1976; Singer et al., 1980; Van Sluyters and Levitt, 1980; Mower et al., 1982; Tremain and Ikeda, 1982; Crewther and Crewther, 1990). This loss of binocularity has been taken to underlie the defects of binocular summation and stereopsis in strabismic animals (von Grünau, 1979) and humans (Lema and Blake, 1977; Levi et al., 1979).

There is a little neurophysiological evidence concerning the possible basis of the harmonious anomalous correspondence and residual stereopsis observed in some strabismic humans. After rearing with optically induced vertical or rotational misalignment of the eyes, Shlaer (1971), Shinkman and Bruce (1977), and Dürsteler and von der Heydt (1983) reported some degree of compensation in the positional or orientational disparity of the receptive fields of surviving binocular cells in kitten striate cortex. In area 18 (Cynader et al., 1984) and in the lateral suprasylvian cortex of strabismic cats (Sireteanu and Best, 1992), some binocular neurons also appear to have receptive fields in anomalously corresponding retinal positions, which might allow registration of the images seen by the two eyes. 
In the majority of cases of strabismus in humans, diplopia and confusion are avoided through suppression of vision in one eye, especially in the central visual field (Sireteanu and Fronius, 1981; Sireteanu, 1982). In people who alternate fixation, such interocular suppression also switches from eye to eye, depending on which eye is currently being used for fixation. In those who habitually fixate with one eye, the other, deviating eye, which commonly suffers strabismic amblyopia, is usually permanently suppressed when both eyes are open. Little is known of the site and nature of the suppressive mechanism, which results in virtual blanking of vision in the nonfixating eye, although psychophysical evidence points to a cortical origin (Blake and Lehmkuhle, 1976; Hess, 1991). Analysis of visual evoked potentials in cats (Sclar et al., 1986) and of the responses of striate neurons (Xue et al., 1987) suggests that binocular summation is generally lost in long-term esotropic cats, while some binocular interactions are retained in the apparently monocularly driven cells found in exotropes (see also Cynader et al., 1984). Interocular inhibition, as assessed by visually stimulating cells through one eye while electrically stimulating the optic nerve of the other side, showed asymmetries in esotropes but not in exotropes (Freeman and Tsumoto, 1983): responses through the deviating eye were more efficiently suppressed by the nondeviating eye than vice versa. Only one very recent study has employed true binocular stimulation, of the kind that actually leads to suppression in humans, to investigate the neural mechanism of suppression in amblyopic cats: detailed analysis of responses of a few binocular units in area 17 showed some disinhibition of the responses through the deviating eye under monocular rather than binocular stimulation (Crewther and Crewther, 1993).

Here, we present electrophysiological evidence that surgically induced strabismus (both exotropia and esotropia) virtually abolishes the disparity-specific binocular interactions that are such a distinctive features of normal striate neurons, but leaves pronounced, nonspecific interocular suppression in the majority of cells.

Parts of the data have been published previously (Sengpiel and Blakemore, 1993, 1994; Sengpiel et al., 1993).

\section{Materials and Methods}

Animals. Data were obtained from five strabismic cats bred in a laboratory colony. For comparison, data are presented from five normal mature cats, in which 76 cells in the striate cortex were studied under identical conditions (cf. Sengpiel et al., 1992, 1994).

Surgical strabismus was induced on postnatal day 10 , that is, just after eye opening. In two cats, the right eye was made exotropic under ketamine hydrochloride general anesthesia and with topical anesthetic (Amethocaine) instilled in the conjunctival sac. Through a small incision in the conjunctiva, the medial rectus muscle was secured with a muscle hook and it was disinserted from its attachment to the globe (tenotomy). In three other animals, esotropia was induced by tenotomy of the lateral rectus of the right eye. Recovery was rapid, with no evidence of pain or distress. The animals were checked frequently for the first few days after surgery, to be sure that the lids of the operated eye remained open and thereafter to ensure that the operated eye did not return to its normal position (a not uncommon occurrence after simple tenotomy). All strabismic animals were reared in an open colony room until at least I year of age.

Prior to the electrophysiological experiments, the fixation patterns of four cats (DS2, CS1, CS2, and CS3) were assessed by means of the cover tests (Duke-Elder, 1973). The animal was held facing the observer, who attracted its attention to his face by making movements and noises with his mouth. A window behind the observer provided a distinct reflection in the cat's corneas, which aided judgement of eye movement. A piece of card was then used to cover and uncover one eye at a time, or was moved quickly from eye to eye, and the resulting patterns of fixation and refixation were judged. Even for the animal with the smallest squint (CS1), we were fairly confident that this procedure established whether the cat habitually fixated with the nonoperated eye (monocular squint) or whether it could hold fixation with either eye (alternating squint). The fifth animal (DS1) had a very large-angle exotropia, and it was evident from the orientation of its head during locomotion and active exploration of moving objects that it habitually employed the nonsquinting eye for fixation. Table 1 summarizes the test results and gives the angle of squint for each cat, estimated from the separation of the projections of the areae centrales during the recording experiment (see below). Values were corrected for the average divergence $\left(4^{\circ}\right)$ of the visual axes observed in normal paralysed cats (Nikara et al., 1968). Although it is difficult to estimate the angle of strabismus accurately in awake cats, we had the feeling that it was usually larger than the value seen under paralysis.

Observation of reflex eye movements during rotation of the head and spontaneous changes of fixation suggested that, in four of the animals, the operated eye was quite mobile and movements were roughly conjugate, except in extreme duction toward the tenotomized muscle. Only in CS2, which had an esotropia of very large angle (Table 1), were movements of the deviating eye much more restricted.

Preparation for recording. Standard electrophysiological techniques for single-cell recording were employed (see Blakemore and Price, 1987). Anesthesia was induced with ketamine hydrochloride $(30 \mathrm{mg} / \mathrm{kg})$ and maintained with alphaxalone/alphadolone (Saffan, Pitman-Moore) intravenously during tracheal cannulation and the exposure of cerebral cortex via a very small craniotomy and durotomy. During recording the animal was anesthetized and paralyzed with a continuous intravenous infusion of sodium pentobarbitone $(1-2 \mathrm{mg} / \mathrm{kg} / \mathrm{hr}$, as needed to maintain anesthesia) and gallamine triethiodide $(10 \mathrm{mg} / \mathrm{kg} / \mathrm{hr})$ in glucose-saline. EEG and ECG were constantly recorded to monitor the state of anesthesia. The animal was artificially hyperventilated with room air plus carbon dioxide $\left(\mathrm{CO}_{2}\right)$, which was adjusted to maintain end-tidal $\mathrm{CO}_{2}$ at $4.5-5.0 \%$. Body temperature was kept at $38^{\circ} \mathrm{C}$ by means of a feedback-controlled heating-pad.

The pupils were dilated with atropine hydrochloride, and the lids and nictitating membrane retracted with phenylephrine. Zero-power contact lenses were fitted and $3 \mathrm{~mm}$ artificial pupils were placed in front of the eyes, as well as additional lenses for correction of refractive errors, which were assessed by objective ophthalmoscopy and by adjusting the lenses to optimize the spatial resolution of individual neurons responding to drifting gratings (see below).

Recording and visual stimulation. Tungsten-in-glass microelectrodes (1.5-2.5 M at $1 \mathrm{kHz}$ ) were advanced, by means of a stepping-motor microdrive, at stereotaxic coordinates corresponding to the representation of the center of the visual field in the primary visual cortex, area 17, of the left hemisphere (P5, L1.5).

In each animal, two to four vertical penetrations were made, and units were recorded from all layers of the primary visual cortex, usually at intervals of about $100 \mu \mathrm{m}$. They were characterized qualitatively with moving and stationary, flashed bars, or spots of light of medium contrast, back-projected by means of an overhead projector on to a translucent tangent screen. Receptive fields were plotted on a reflected image of the tangent screen, on which the projections of the areac contralcs and the optic disks were also mapped by means of a reversible ophthalmoscope. Neurons were classified as simple or complex, according to Blakemore and Price's (1987) description of Hubel and Wiesel's (1962) original criteria. The ocular dominance (OD) of cortical neurons was classified on the seven-point scale of Hubel and Wiesel (1962).

For quantitative tests, the two eyes were stimulated independently by means of two high-resolution display screens (Tektronix 608) viewed at a distance of $57 \mathrm{~cm}$ via front-silvered mirrors. The total display area on each screen consisted of a circular region subtending $10^{\circ}$ of visual angle in diameter. The screens were adjusted in position to bring the receptive fields to the centers of the displays. In case of monocular units, the display for the "silent" eye was centered on the appropriate position, determined by mapping background activity or by prior recording from neighboring cells dominated by that eye.

Drifting, sinusoidally modulated gratings that filled the entire display area (mean luminance of $17.5 \mathrm{~cd} / \mathrm{m}^{2}$ ) were generated by a PICAsso (Innisfree, Cambridge, MA) image synthesizer. External control of the PICASSO as well as data acquisition and analysis were performed by a visUAL STIMULATION software package (vs, Cambridge Electronic Design, Cambridge, UK). This package allows the pseudorandom inter- 
leaving of a variety of different stimuli, including a blank stimulus with no modulated pattern on the screen. Responses were averaged over a number of presentations of each individual stimulus included in the sequence. Directions, and hence orientations, were specified according to a sign convention in which zero corresponds to rightward motion of a vertical grating, upward drift of a horizontal grating is $90^{\circ}$, leftward movement of a vertical grating is $180^{\circ}$, and downward motion of a horizontal grating is $270^{\circ}$.

Cells were first stimulated monocularly with gratings, drifting at a temporal frequency optimized by ear, to determine "tuning curves" for orientation, direction, and spatial frequency. During these trials, a uniform field of the same space-averaged luminance was presented to the corresponding region of the visual field of the other eye. Each individual presentation lasted $1.25 \mathrm{sec}$, while the blank periods between presentations lasted $1 \mathrm{sec}$.

Binocular interactions were then tested by constantly stimulating the dominant eye with a full-field $\left(10^{\circ}\right.$ diameter) drifting grating (the "conditioning" stimulus) of optimum orientation and spatial frequency and medium contrast $[0.18-0.35$, where contrast $=$ (maximum - minimum luminance $) /(2 \times$ mean luminance $)]$, and intermittently presenting to the other eye drifting gratings varying in orientation, spatial frequency, or contrast. In some experiments, the spatial offset (phase of the triggering point) of the grating shown to the nondominant eye was varied while holding the relative phase of the "conditioning" (dominant-eye) grating constant. When both stimuli are optimally oriented, such a spatial offset corresponds to relative interocular phase disparity (Ohzawa and Freeman, 1986a). The two gratings always drifted at the same temporal frequency-either 2 or $4 \mathrm{~Hz}$. Each epoch of binocular stimulation lasted $5 \mathrm{sec}$ and the periods of monocular stimulation between also lasted $5 \mathrm{sec}$, unless specified otherwise.

Mean discharge rates and standard errors of the mean were calculated from at least four trials with each condition. Tuning curves of interaction were obtained by relating the mean response for each particular binocular presentation to the mean response during the immediately preceding periods of monocular stimulation. A cell was considered to show binocular interaction if the response during binocular stimulation differed significantly (in a two-tailed $t$ test) in strength from that for stimulation of the dominant eye alone. In some cases, peristimulus time histograms (PSTHs) were accumulated and averaged in order to examine in detail the pattern of response during the introduction of a grating to the nondominant eye while the cell was responding to an optimum "conditioning" stimulus in the other eye.

In four cells that showed clear interocular suppression in the standard procedure (but which were not exceptional in any other way), the effects of different temporal sequences of presentation were studied in detail. The response was averaged over a $5 \mathrm{sec}$ period of binocular stimulation with gratings of identical orientation and spatial frequency (optimal for the dominant eye), preceded by either (1) a blank screen of the same mean luminance presented to both eyes, (2) the grating presented alone to the nondominant eye alone, or (3) the "conditioning" grating shown to the dominant eye alone.

Histology. Electrode tracks were marked with small electrolytic lesions made at intervals during withdrawal of the electrode. Animals were given an overdose of pentobarbitone and perfused transcardially with phosphate-buffered saline followed by $4 \%$ paraformaldehyde. Electrode tracks were reconstructed from $50 \mu \mathrm{m}$ coronal sections stained with cresyl violet.

\section{Results}

In the two exotropic animals we recorded from 87 cells in the striate cortex, 38 of which (11 simple, 27 complex) were quantitatively tested for binocular interaction, after initial monocular characterization. In the three esotropic animals, 112 units were recorded and 47 were tested binocularly (12 simple, 35 complex). The receptive field centers of all cells were within $4^{\circ}$ of the area centralis.

Stimulation of the nondominant eye significantly affected the response to stimulation through the dominant eye in some way for 28 cells from exotropic animals $(74 \%$ of the total of 38 quantitatively analyzed units) and for 30 cells ( $64 \%$ of the total of 47) recorded from esotropic cats.

\begin{tabular}{|c|c|c|}
\hline Animal & $\begin{array}{l}\text { Direction and } \\
\text { angle of squint }\end{array}$ & Fixation pattern \\
\hline DS1 & $\operatorname{exo} 30^{\circ}$ & nonoperated eye only \\
\hline DS2 & $\operatorname{exo} 8^{\circ}$ & alternating \\
\hline $\mathrm{CS} 1$ & eso $4^{\circ}$ & nonoperated eye only \\
\hline CS2 & eso $34^{\circ}$ & nonoperated eye only \\
\hline CS3 & eso $10^{\circ}$ & nonoperated eye only \\
\hline
\end{tabular}

In general, the angle of strabismus appeared larger in the awake animal. The fixation patterns of the cats were judged from cover tests, except for DSl (see Materials and Methods). DS, divergent strabismus; CS, convergent strabismus.

\section{Monocular response properties}

As expected, the fraction of striate neurons receiving suprathreshold excitatory inputs from both eyes was distinctly lower in all the strabismic animals than in normal cats. In only 62 cells $(31 \%)$ of the total of 199 units, responses could be elicited through stimulation of either eye alone ("binocular" cells), compared to $91 \%$ in the sample of 76 units recorded from five normal animals under identical conditions. These values are in good agreemcnt with the results of previous studies, which have shown between $15 \%$ and $31 \%$ binocular units in squinting cats and from $80 \%$ to $91 \%$ in normal animals studied with similar techniques (e.g., Hubel and Wiesel, 1962, 1965; Blakemore, 1976; Van Sluyters and Levitt, 1980; Mower et al., 1982; Crewther and Crewther, 1990). For the individual strabismic animals, the fraction of neurons that were exclusively driven through one eye [ocular dominance (OD) groups 1 or 7; Hubel and Wiesel, 1962 ] varied between $56 \%$ (in cat CS2) and $76 \%$ (in CS3). Only $3 \%$ of all cells were equally well driven through the two eyes (OD group 4), compared to $26 \%$ in the normal animals. OD distributions for each of the five strabismic cats, as well as an accumulated histogram of the data from the five normal animals, are shown in Figure 1. Four of the five strabismic animals showed no obvious bias in the OD distribution toward either eye. Only in CS1 ( $4^{\circ}$ of esotropia) was the histogram apparently skewed toward the nondeviating eye. However, the 46 units from this animal were recorded along three electrode tracks angled almost perpendicular to the cortical surface; therefore, the nominally statistically significant skewing of the OD distribution ( $\chi^{2}$ test, $p<0.005$ ) might have been produced by uneven sampling across the OD columnar pattern of the cortex. On the other hand, it must be said that similar biases, and always toward the nonsquinting eye, have been reported by others for esotropic cats with definite amblyopia in the deviating eye (Mower et al., 1982; Tremain and Ikeda, 1982), although others have failed to confirm such a shift in OD (Crewther and Crewther, 1990). Certainly there was no consistent difference between the form of the OD distribution in the animals that habitually fixated with their nonoperated eye and the one animal (DS2) with alternating fixation (which presumably did not have severe amblyopia).

Apart from the breakdown of binocularity, cells recorded in the strabismic cats did not show any obvious abnormalities, irrespective of whether they were dominated by the normal or the operated eye. We saw neither unusual scatter of receptive field positions in the operated eye (cf. Yinon et al., 1975) nor any evidence of a shift of correspondence to compensate for the 


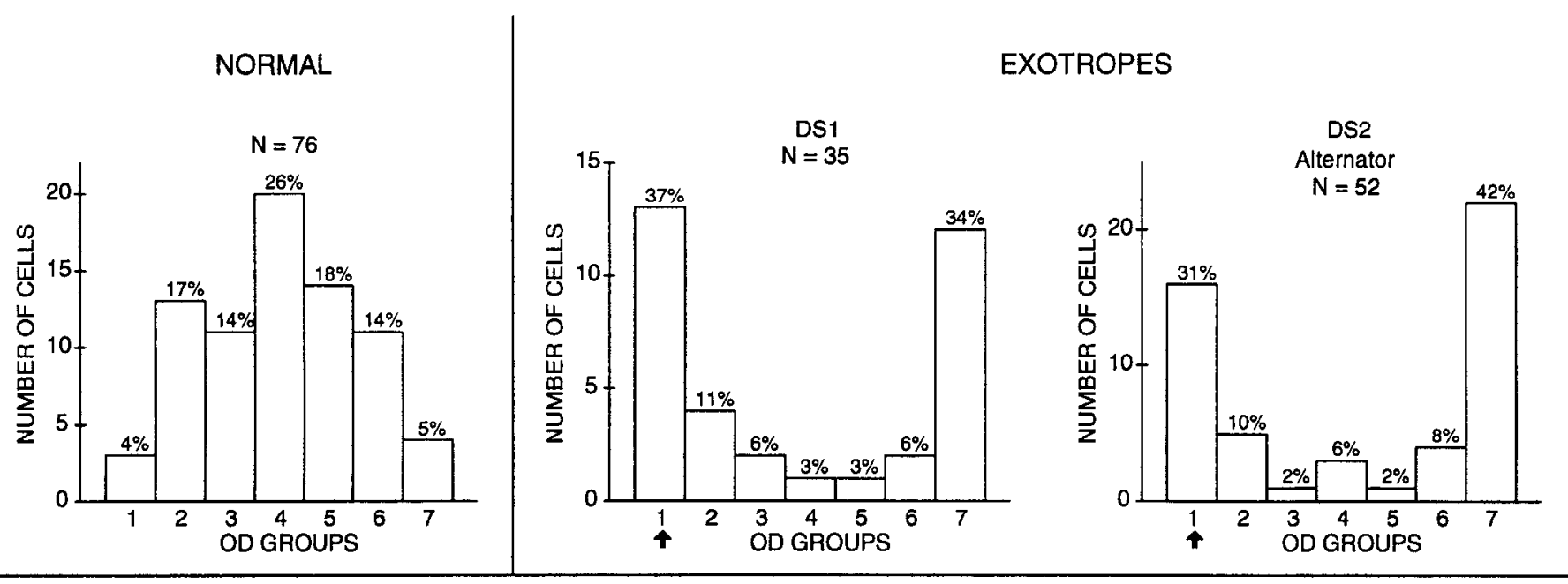

ESOTROPES
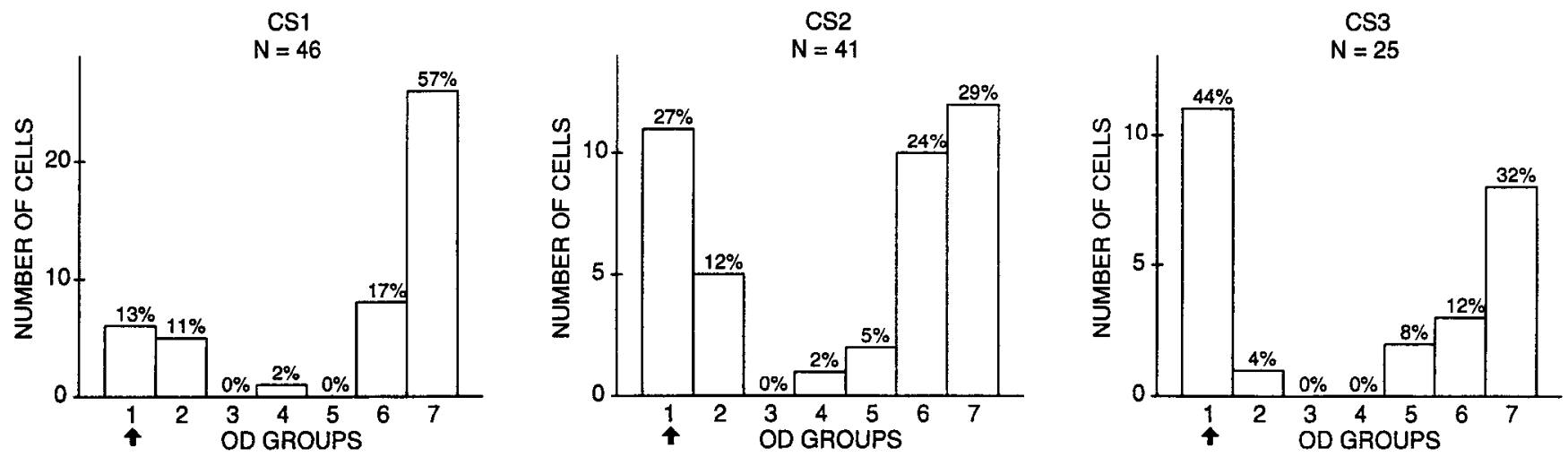

Figure 1. Ocular dominance (OD) distributions of cells recorded from normal and strabismic cats. The top left histogram (NORMAL) shows accumulated data from five normal animals, while the remaining histograms represent individual OD distributions for each of the five strabismic animals, subdivided into exotropes (one, DS2, being the only animal with alternating fixation) and esotropes. Animal identification (see Table 1) and the total number of cells recorded are given at the top of each histogram. Neurons were classified in one of seven ocular dominance groups followed the scheme devised by Hubel and Wiesel (1962): cells in groups 1 and 7 were monocularly driven by the contralateral and ipsilateral cyc, respectively; cells in group 4 are equally responsive through the two eyes. Since recordings in the squinting animals were taken from the hemisphere contralateral to the operated eye, OD group 1 (arrows) signifies complete dominance by the operated eye, while OD group 7 represents cells exclusively driven through the nonoperated eye.

squint [as reported by Shlaer et al. (1971), Cynader et al. (1984), and by Sireteanu and Best (1992), for some neurons in area 17, area 18 , and the lateral suprasylvian cortex, respectively]. In each penetration, all the receptive fields encountered, of both monocular and binocular cells, were in roughly corresponding points in the two eyes (relative to the projections of the areae centrales). However, the large angles of strabismus in all animals but CS1 might have precluded compensatory shifts in receptivefield disparity.

The sharpness of orientational tuning was quantitatively assessed, for a sample of cells dominated by each eye in all strabismic cats, by performing a Fourier analysis of the responses to drifting gratings varied pseudorandomly in drift direction (see Wörgötter et al., 1990). Curves were fitted to the data points, taking into account the $0-8$ th order Fourier components, and tuning widths wcrc calculated. For 33 cells dominated by the operated eye, the mean half-width at half-height was $24.4 \pm$ $8.3^{\circ}( \pm \mathrm{SD})$. For 48 cells dominated by the nondeviated eye, mean half-width at half-height was $21.3 \pm 8.4^{\circ}$, and for 44 cells recorded from normal animals the mean value was $22.2^{\circ} \pm 7.0^{\circ}$, similar to that reported by others (e.g., Henry et al., 1974; Rose and Blakemore, 1974). Thus, in accordance with the majority of previous studies (e.g., Hubel and Wiesel, 1965; Freeman and Tsumoto, 1983; Kalil et al., 1984; but see Chino et al., 1983), the narrowness of orientational tuning seemed unaffected by strabismus, even for cells driven by the operated eye.

Although the precision of orientational selectivity of cells dominated by the squinting eye appeared unimpaired, the distribution of preferred orientations of cells recorded from strabismic cats differed markedly from that found in the normal control animals (Fig. 2). While in the latter all orientations were roughly equally represented, neurons from the squinting cats showed a clear bias toward vertical preferred orientations, irrespective of whether cells were dominated by the operated or the nonoperated cyc, and whether they were monocularly or binocularly driven: the proportion of binocular cells with preferred orientations near vertical $\left( \pm 22.5^{\circ}\right)$ was only slightly lower $(42 \%)$ than that of the total population $(50 \%)$. While confirming 
a study by Kalil et al. (1984), these findings contrast with those reported by Singer et al. $(1979,1980)$ and Cynader et al. (1984) of an underrepresentation of vertical orientation preferences in areas 17 and 18 , respectively, of strabismic cats. The inconsistency of these studies could simply be the result of biases in the sampling across orientation columns.

Tuning curves for spatial frequency were determined by measuring responses to gratings of optimal orientation and direction of motion, all drifting at the same temporal frequency but varying pseudorandomly in spatial frequency from presentation to presentation. The value of spatial frequency at which the response of the cell fell to the spontaneous level, on the highfrequency side of the tuning curve, was taken as the "neural acuity" or cutoff spatial frequency of the cell. Although the sample of quantitatively analyzed cells dominated by the operated eye was relatively small, in none of the five strabismic cats were cutoff frequencies significantly lower for cells dominated by the operated eye than for those dominated by the nonoperated eye of the same animal, although a minor (nonsignificant) difference, by an average of 0.3 cycle/degree, was found in esotropic cat CS1. This confirms results of Blakemore and Eggers (1978) from three exo- and three esotropic animals with tenotomy-induced squint. However, we did not systematically test acuity in binocular cells, in particular, those dominated by the nonsquinting eye, for which Crewther and Crewther (1990) have reported small differences in the mean acuity through the two eyes correlated with the presence of amblyopia.

\section{Strabismus virtually eliminates orientation-dependent binocular facilitation}

For disparity-selective cells in area 17 of normal cats (e.g., Barlow et al., 1967; Nikara et al., 1968; Ohzawa and Freeman, $1986 \mathrm{a}, \mathrm{b})$, including a proportion of those that appear to be monocularly driven (Kato et al., 1981), simultaneous stimulation of both eyes with iso-oriented gratings produces facilitation or summation at one relative interocular phase and often yields occlusion when the gratings are out of phase in the two eyes). We studied binocular interaction by presenting a sequence of stimuli to the cell's nondominant eye while continuously stimulating the dominant eye with an optimum drifting grating. In order to search for conventional disparity-selective interactions, the gratings were of identical orientation, direction, and spatial and temporal frequency (optimum for the dominant eye) in the two eyes but their relative spatial phase (or disparity) was changed pseudorandomly from exposure to exposure.

Table 2 summarizes results on binocular interaction, separately for cells dominated by the nonoperated eye, cells dominated by the operated eye, and those with equal excitatory input from the two eyes (OD group 4). Of 85 cells tested in all five strabismic animals, only eight $(9 \%)$ showed any enhancement of the monocular response when a grating of the same orientation was introduced into the other eye, whatever its spatial phase, and only five exhibited genuine facilitation in the sense that the binocular response was more than the sum of the monocular responses (see Fig. $3 A$ for an example). All but one of the eight neurons demonstrating some degree of binocular enhancement (which were encountered in all layers of the cortex) were initially classified as binocularly driven (i.e., responsive through either eye alone) and they included all four cells of OD group 4 (see Table 2) and three of the eight cells that were only slightly dominated by one eye (OD groups 3 and 5). For these cells, the amount of summation (or facilitation) did not vary
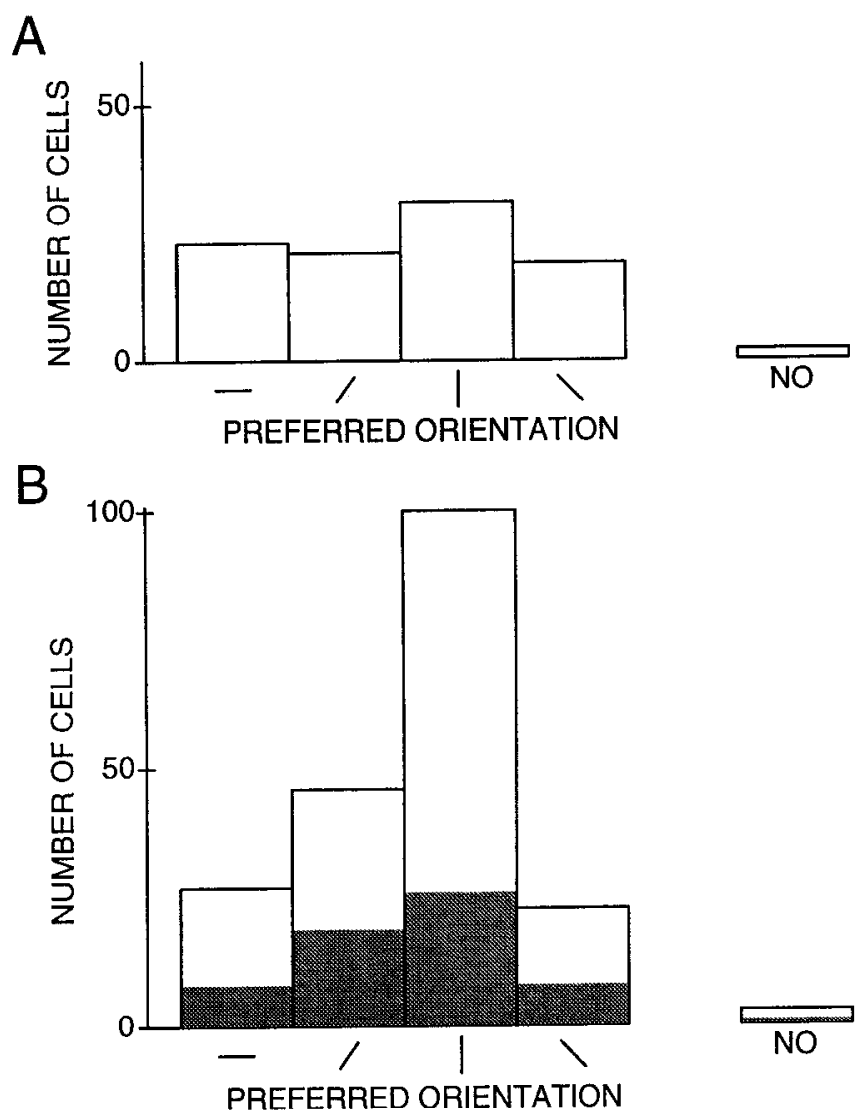

Figure 2. Distribution of preferred orientation for 96 cells recorded from V1 in six normal cats $(A)$ and 199 cells from five strabismic cats $(B)$. Numbers of cells are plotted against orientation preference, classified into one of four bins of $\pm 22.5^{\circ}$, corresponding to near-vertical, near-horizontal, and near-oblique (indicated by bars below histograms). The shaded bars in $B$ represent binocular cells (OD groups 2-6).

significantly with the relative interocular phase (disparity) of iso-oriented gratings, with one exception (Fig. 4): the only simple cell in this group (recorded from CS1, with small-angle esotropia) showed a weak cyclical variation of the strength of facilitation (but no occlusion), indicative of rudimentary disparity sensitivity.

We have recently shown that the majority of binocular neurons in the striate cortex of normal cats show interocular suppression when stimulated with gratings of very different orientation in the two eyes, under conditions identical to those used in this study (Sengpiel et al., 1992, 1994; Sengpiel and Blakemore, 1994).

Among the seven binocular cells in strabismic animals that exhibited binocular summation or facilitation for matched gratings, five showed varying degrees of suppression when the grating in the nondominant eye was orthogonal or near-orthogonal to the "conditioning" grating being presented in the dominant eye. Figure 5 illustrates such interocular interactions for a complex cell in exotrope DS1. Polar plots in Figure $5 A$ represent direction/orientation tuning obtained through each eye. In Figure $5 B$, the dominant (operated) eye was continuously stimulated with an optimally oriented, drifting grating, while gratings of various directions of drift (and therefore different orientations) were presented intermittently, in pseudorandom sequence, to the corresponding region of the visual field in the other (normal) eye. Solid circles plot responses during these 

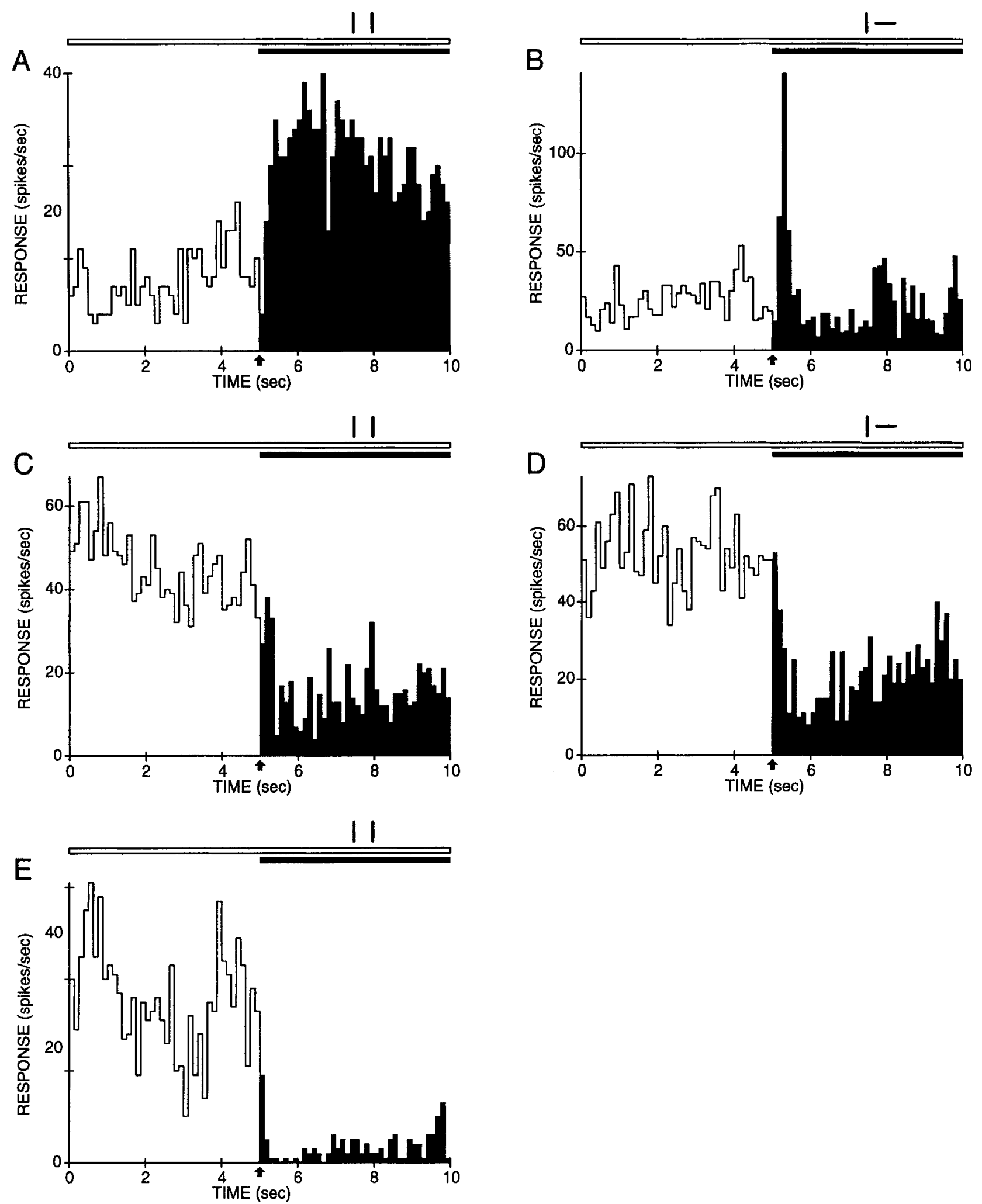

Figure 3. Peristimulus time histograms (PSTHs) chosen to represent the variety of responses observed during binocular stimulation in strabismic cat cortex. PSTHs were accumulated over 6-10 trials; bin width, $125 \mathrm{msec}$. Each cell was initially stimulated with a grating of optimal orientation and spatial frequency (contrast $=0.35$ ) through the dominant eye alone (indicated by an open horizontal bar above the histogram). After 5 sec (marked with an arrow) a grating of the same spatial frequency (contrast $=0.7$ ) and either the same orientation (indicated as $t w o$ short vertical bars above PSTH) or orthogonal orientation (short vertical and horizontal bars) appeared in the nondominant eye. Binocular exposure continued for the 5 sec period marked by the solid bar. A, Complex cell from exotrope DS1, slightly dominated by the operated eye (OD group 3), displaying close-to-normal tonic facilitation for iso-oriented gratings. $B$, Complex cell from esotrope CSI, exclusively driven through the operated eye (OD group 1). This was the only apparently monocular cell that exhibited some excitatory binocular interaction, in the abnormal form of a clear but transient augmentation of the response (lasting for only about $0.6 \mathrm{sec}$ ) immediately after the appearance of the grating in the silent eye. This effect was seen for gratings of any orientation, even orthogonal to optimum, presented to the silent eye. The tonic discharge over the remainder of the 5 


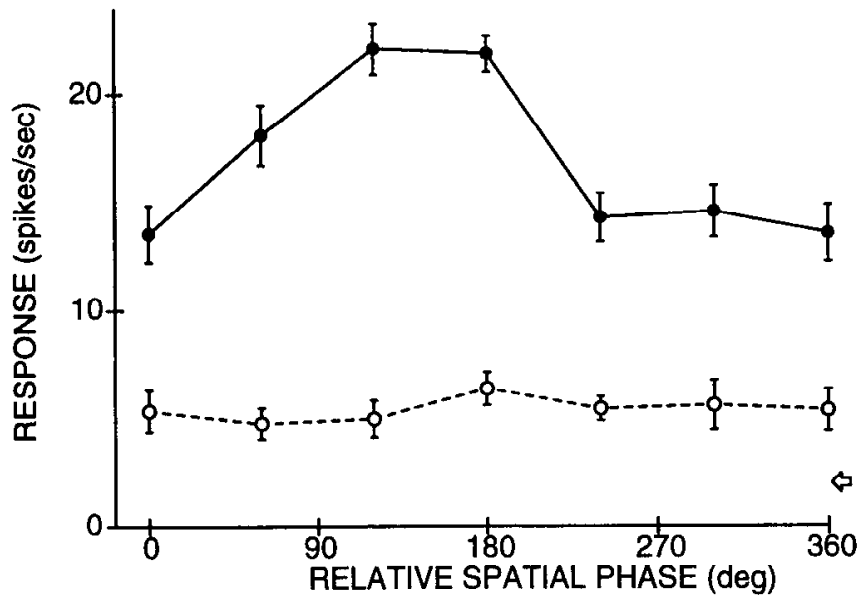

Figure 4. Binocular responses for a simple cell, recorded in esotrope CS1, which was equally responsive through either eye alone (OD group 4). The triggering point of the optimally oriented drifting grating presented to the operated eye (contrast $=0.35$; spatial frequency $=0.56$ cycle/degree, i.e., cycles per degree of visual angle) was fixed at an arbitrary value, while that of the iso-oriented grating presented to the other eye was varied in phasc. Mcan responses in spikes/sec ( \pm SEM, $n$ $=4$ presentations per data point) are plotted against the relative spatial phase or phase angle between the two gratings. Open circles plot the control values during preceding periods of monocular stimulation.

binocular presentations as a function of interocular difference in orientation, while the corresponding open circle at each position on the abscissa plots the mean discharge during the periods of monocular stimulation immediately preceding binocular presentations with that particular combination of orientations.

To our surprise, 28 of the 35 binocularly driven cells tested (80\%) did not show any augmentation of the response to a grating in the dominant eye alone when an identical grating was added to the nondominant eye, whatever its relative spatial phase, despite the fact that the latter stimulus would make the cell respond when presented on its own.

Apart from one unit that displayed a transient augmentation of response (Fig. $3 B$ ), none of the remaining 49 apparently monocularly driven units tested showed any increase in response during binocular stimulation, whatever the relative orientation and spatial phase of the gratings. Indeed, 30 of them $(60 \%)$ exhibited consistent interocular suppression, whatever the stimulus in the silent eye (see below and Table 2).

\section{Orientation-independent interocular suppression}

The majority of all cells, even 17 of the 35 that responded to stimulation of either eye alone, were profoundly suppressed when the nondominant eye was stimulated while the cell was responding to an optimal grating in the dominant eye: the level of response was reduced by up to $90 \%$ compared to that elicited monocularly through the dominant eye. Unlike in normal animals (Sengpiel et al., 1992, 1994; Sengpiel and Blakemore, 1994), this interocular suppression was usually virtually inde-
A
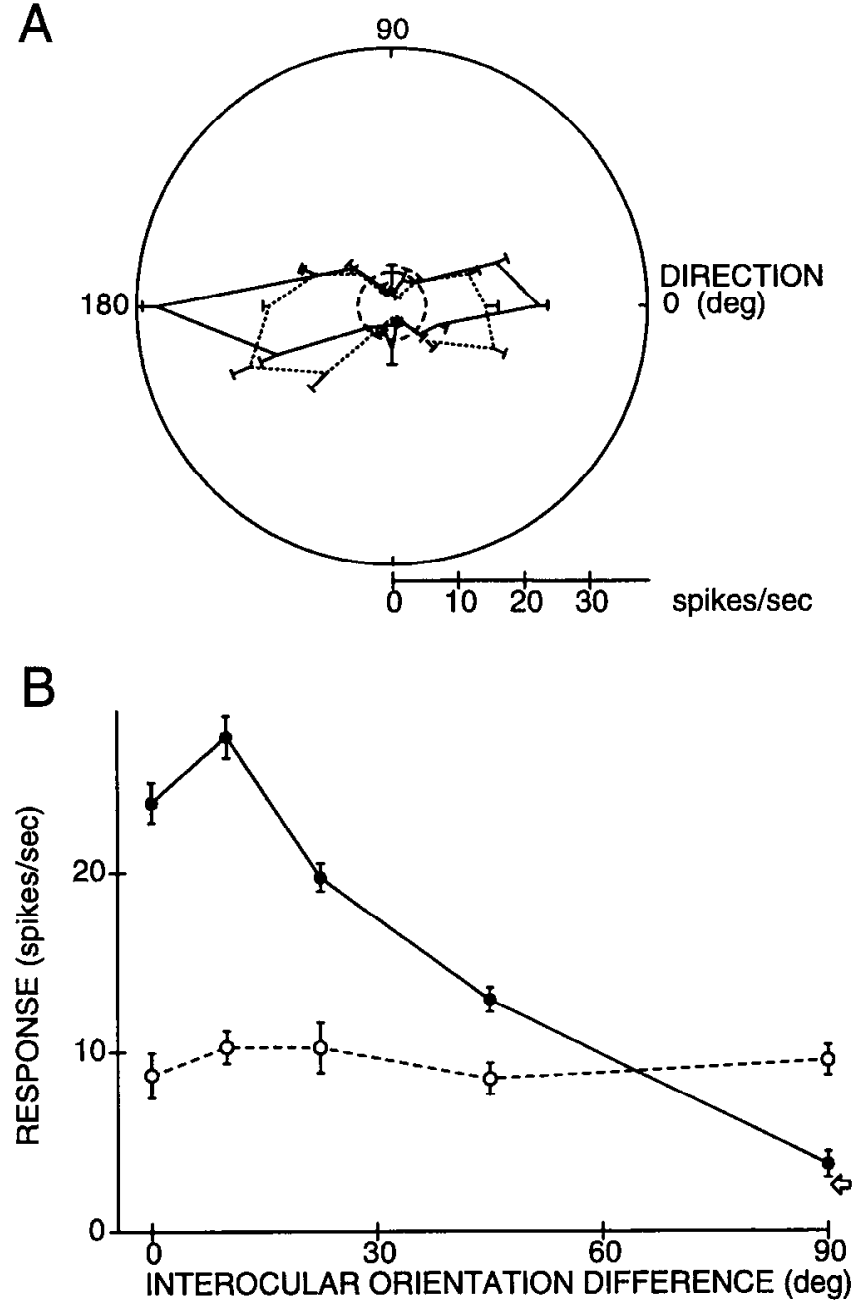

Figure 5. Orientation dependence of binocular interactions in a layer 5 complex cell from exotrope DS1. This cell (the same as in Fig. $3 A$ ) was slightly dominated by the operated eye (OD group 3). $A$, Polar plot of monocular orientation tuning through the deviating (dominant) eye (solid lines) and the normal (nondominant) eye (dotted lines). Mean responses $( \pm$ SEM, $n=4)$ are plotted as a function of the direction of drift of a grating (contrast $=0.7)$ of optimal spatial frequency $(0.56$ cycle/degree) presented to one eye alone. The dashed circle in the center indicates the mean level of spontaneous discharge. $B$, Results of the binocular interaction protocol. The dominant eye was continuously stimulated with a "conditioning" stimulus whose direction of drift was $180^{\circ}$, corresponding to the optimum obtained from the polar plot in $A$ (contrast $=0.18$; spatial frequency $=0.56$ cycle/degree). The abscissa indicates the difference in orientation between the stimuli shown to the two eyes. Gratings (contrast $=0.7$; spatial frequency $=0.56 \mathrm{cycle} / \mathrm{degree}$ ) were presented to the nondominant (normal) eye at five different orientations, over a $90^{\circ}$ range, clockwise from the orientation of the optimal "conditioning" stimulus. Each solid circle ( \pm 1 SEM, $n=6$; joined by solid lines) plots the mean firing rate during the periods of binocular stimulation with gratings differing in orientation (and direction of drift) in the two eyes by the angle shown on the abscissa. Each open circle ( \pm 1 SEM, $n=6$; linked by dashed lines) plots mean responses during the periods of monocular stimulation preceding those presentations with the particular combination of gratings plotted on the abscissa. The arrow indicates the mean level of spontaneous discharge, measured during blank presentations. through the nonoperated eye (OD group 7). For this cell, the latency of orientation-independent suppression was around $375 \mathrm{msec}$ for both isooriented $(C)$ and orthogonally oriented gratings $(D)$. $E$, Complex cell from exotrope DS1, dominated by the deviated eye (OD group 1). This cell exhibited interocular suppression, with relatively rapid onset, irrespective of interocular orientation difference. 
Table 2. Occurrence of orientation-dependent summation (or facilitation) and orientation-independent suppression in area 17 of strabismic cats

\begin{tabular}{|c|c|c|c|c|c|c|}
\hline \multirow[b]{2}{*}{$\mathrm{Cat}^{a}$} & \multirow{2}{*}{$\begin{array}{l}\text { Eye dominant } \\
\text { for cell }\end{array}$} & \multirow{2}{*}{$\begin{array}{l}\text { Total } \\
\text { tested }\end{array}$} & \multirow{2}{*}{ Summation } & \multirow{2}{*}{$\begin{array}{l}\text { Suppres- } \\
\text { sion }\end{array}$} & \multicolumn{2}{|c|}{$\begin{array}{l}\text { Depth of suppression } \\
\text { (mean } \pm \text { SD) for }\end{array}$} \\
\hline & & & & & $\Delta \mathrm{Or}=0^{\circ}$ & $\Delta \mathrm{Or}=90^{\circ}$ \\
\hline \multirow[t]{3}{*}{$\mathrm{DS} 1$} & Normal & $11(8)$ & 0 & $9(7)$ & $67 \pm 16 \%$ & $60 \pm 14 \%$ \\
\hline & Exo & $9(3)$ & 1 & $6(2)$ & $51 \pm 26 \%$ & $58 \pm 32 \%$ \\
\hline & OD group 4 & 0 & 0 & 0 & - & - \\
\hline \multirow[t]{3}{*}{ DS2 (alternator) } & Normal & $9(5)$ & 0 & $5(3)$ & $56 \pm 21 \%$ & $45 \pm 33 \%$ \\
\hline & Exo & $7(4)$ & 0 & $4(2)$ & $46 \pm 4 \%$ & $48 \pm 16 \%$ \\
\hline & OD group 4 & 2 & 2 & 0 & - & - \\
\hline \multirow[t]{3}{*}{$\mathrm{CS} 1$} & Normal & $10(6)$ & 0 & $6(3)$ & $47 \pm 20 \%$ & $44 \pm 8 \%$ \\
\hline & Eso & $6(3)$ & $1(1)$ & 0 & - & - \\
\hline & OD group 4 & 1 & 1 & 0 & - & - \\
\hline \multirow[t]{3}{*}{$\mathrm{CS} 2$} & Normal & $11(6)$ & 2 & $5(4)$ & $60 \pm 16 \%$ & $55 \pm 14 \%$ \\
\hline & Eso & $7(5)$ & 0 & $5(3)$ & $55 \pm 9 \%$ & $44 \pm 12 \%$ \\
\hline & OD group 4 & 1 & 1 & 0 & - & - \\
\hline \multirow[t]{3}{*}{$\mathrm{CS} 3$} & Normal & $8(7)$ & 0 & $7(6)$ & $48 \pm 27 \%$ & $45 \pm 16 \%$ \\
\hline & Eso & $3(3)$ & 0 & 0 & - & - \\
\hline & OD group 4 & 0 & 0 & 0 & - & - \\
\hline
\end{tabular}

Numbers in parentheses refer to strictly monocular units (OD group 1 or 7). The final two columns give the average percentage suppression, below the monocular level, caused by an iso-oriented grating ( $\Delta \mathrm{Or}=0^{\circ}$ ) and an orthogonally oriented grating $\left(\Delta \mathrm{Or}=90^{\circ}\right.$ ) presented to the nondominant eye, for all cells judged to show suppression independent of orientation. There were no obvious differences between strabismic animals (whether esotropic or exotropic, alternators or nonalternators) in the proportion of cells showing binocular summation. It is worth noting that the mean depth of suppression was stronger, though only slightly, in the animals with large-angle squints (DS1, CS2) than in the others.

See Table 1 .

pendent of the orientation of gratings shown to the nondominant eye (see Fig. $3 C, D$ ), whatever the relative spatial phase. This was the case for 24 units (63\% of the total) from exutropic animals as well as for 23 units (49\% of the total) from the esotropes (see Table 2).

Figure 6 shows an example of a monocularly driven complex cell, recorded in the large-angle esotropic cat, CS2. Figure $6 \mathrm{~A}$ is a polar plot showing the orientation tuning of this neuron for stimulation through the dominant, nondeviating eye. Figure $6 B$ illustrates binocular interactions in the same manner as Figure $5 B$, plotting the binocular response (solid circles) against the difference in orientation between the optimum grating being presented in the dominant eye and the gratings of various orientations shown to the silent (deviating) eye. To take account of any chance fluctuations in responsiveness, as indicated by variation in the monocular control values (open circles), the level of response during binocular stimulation was calculated as a percentage of the corresponding monocular response: [(binocular response - monocular response)/(monocular response - spontaneous discharge) $] \times 100 \%$. Figure $6 C$ plots these values as a binocular interaction function: interocular suppression (about $75 \%$ reduction in response for this cell) was essentially independent of the orientation of the grating shown to the silent eye. Further examples of nonselective suppression are shown for two simple cells recorded in exotropic animals, one dominated by the nonoperated eye of the nonalternator, DS1 (Fig. 7), the other dominated by the operated eye of the alternator, DS2 (Fig. 8).

Orientation-independent suppression was seen for cells in all cortical layers but was more frequent among neurons from supragranular layers (33 of 51 units) and infragranular layers (8 of 12) than those recorded in layer 4 (6 of 22).

\section{Suppression depends on the sequence of stimulus presentation}

The strong interocular suppression that we saw in such a large proportion of neurons from strabismic animals might be thought to contradict the preliminary observations of Xue et al. (1987), who reported that long-term squint results in a complete loss of binocular interaction. However, Sengpiel and Blakemore (1994) have recently shown that interocular suppression in the cortex of both normal and strabismic cats is strong only when the suppressive stimulus in one eye is introduced against a preexisting background response to an optimal stimulus in the other eye. As Figure 9 shows, for a typical monocularly driven complex cell from esotrope CS2, binocular stimulation with simultaneous onset in the two eyes (as employed by Xue et al., 1987) does not lead to suppression, while staggered onset does.

For the PSTHs in Figure $9 A-C$, spikes were accumulated over $10 \mathrm{sec}$ stimulus presentations, the second half of which always consisted of simultaneous stimulation of both eyes with gratings of identical orientation, optimal for the dominant eye. The only difference between these experimental runs was the nature of stimulation during the 5 sec period immediately preceding each binocular presentation, which was (A) a blank screen of the same mean luminance presented to both eyes, (B) the grating shown alone to the nondominant eye, or $(\mathrm{C})$ the optimum grating presented alone to the dominant eye. For further control data, we also examined the response as a function of contrast during 5 sec presentations of the optimal grating to the dominant eye alone with the other eye viewing only a blank screen, preceded by either (I) a blank screen to both eyes, or (II) an initial $5 \mathrm{sec}$ period of stimulation of the dominant eye.

Comparison of these five conditions (Fig. 9D) reveals no sig- 
A
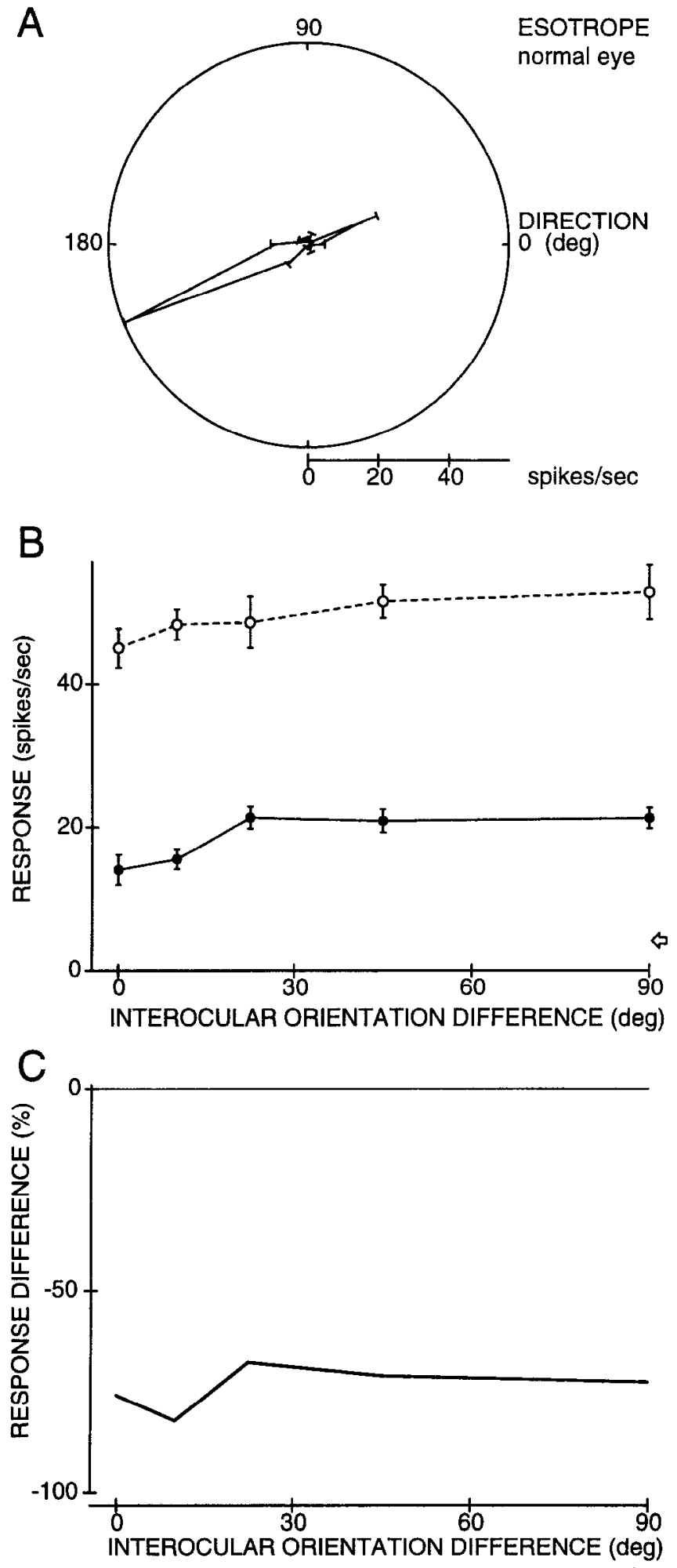

Figure 6. Orientation tuning of binocular interactions in a layer $2 / 3$ complex cell recorded in esotropic cat CS2, which was monocularly driven through the normal (ipsilateral) eye (OD group 7). $A$, Mean response ( \pm SEM, $n=4)$ is plotted on polar coordinates as a function of the direction of drift of a grating (contrast $=0.7$; spatial frequency $=0.56 \mathrm{cycle} /$ degree) presented to the dominant (normal) eye alone. $B$, Results of the binocular interaction protocol, as in Figure $5 B$. The dominant eye was continuously stimulated with a "conditioning" stimulus whose direction of drift was $202.5^{\circ}$, corresponding to the optimum obtained from the polar plot in $A$ (contrast -0.35 ; spatial frequency $0.56 \mathrm{cycle} / \mathrm{degree})$. The abscissa indicates the difference in orientation nificant difference in the magnitude of the response during the second 5 sec epoch of each condition, except for condition $C$, where the sudden introduction of a stimulus in the "silent" eye while the cell is already responding through the dominant eye results in dramatic suppression.

\section{Suppression results from a reduction in contrast gain}

The decrease in response during suppression could be due to either a shift of the threshold of the cell to higher contrasts without a change in contrast gain (response vs contrast), or to a decrease of the slope of the contrast gain function. Sengpiel and Blakemore (1994) have suggested that there is a change in slope with little shift in threshold. We examined this question for three apparently monocular cells and one weakly binocular neuron that showed clear suppression but were not distinctive in any other way. Stimuli were presented according to the procedure described above for Figure 9 . In each run, the contrast of the suppressive grating in the nondominant eye was fixed at 0.7 but that in the dominant eye was varied from trial to trial, providing data for the construction of contrast gain functions for each of the five experimental and control conditions (see above). For each cell, these functions were very similar for all control and experimental conditions except for condition $\mathrm{C}$, which results in suppression.

In Figure 10, average firing rate over the second $5 \mathrm{sec}$ period in each trial is plotted against the contrast of the grating in the dominant eye. Open circles plot results for the control condition II (stimulation through the dominant eye alone), while solid circles show responses in the suppressed statc [condition C]. Figure $10 A$ shows results for the same cell as for Figure 9, while Figure $10 B-D$ summarizes the results for three more fully analyzed cells. The pattern was similar for all four cells: the reduction in response was greater the higher the contrast of the stimulus in the dominant eye (with contrast in the "suppressing eye" being fixed), and the control and suppressed curves meet very close to the level of background activity. In other words, suppression results from a reduction in the slope of the contrastresponse curve (contrast gain). Although we did not systematically measure the contrast thresholds of cells in the suppressed and unsuppressed states, extrapolation of the gain curves back to the level of background activity in each part of Figure 10 suggests that there is little difference in threshold.

\section{Suppression in exotropic and esotropic animals}

For all animals, the incidence and magnitude of interocular suppression are summarized in Table 2 . In both exotropic an-

between the stimuli shown to the two eyes. Gratings (contrast $=0.7$; spatial frequency -0.8 cycle/degree) were presented to the silent (dcviated) eye at five different orientations, over a $90^{\circ}$ range, clockwise from the orientation of the optimal "conditioning" stimulus. Solid circles $( \pm 1$ SEM, $n=8$ ) plot the mean firing rate during binocular stimulation with gratings differing in orientation in the two eyes by the angle shown on the abscissa. Each open circle $( \pm 1$ SEM, $n=8)$ plots mean responses during the periods of monocular stimulation preceding those presentations with the particular combination of gratings plotted on the abscissa. The arrow indicates the mean level of spontaneous discharge. Note that even identically oriented gratings (zero on the abscissa) produced strong suppression. $C$, Binocular interaction function, plotting the response during binocular stimulation, expressed as a percentage of the corresponding monocular response (see text), at each interocular orientation difference. Strength of suppression was constant (about 75\% of the monocular responses) over the range of orientation differences tested. 

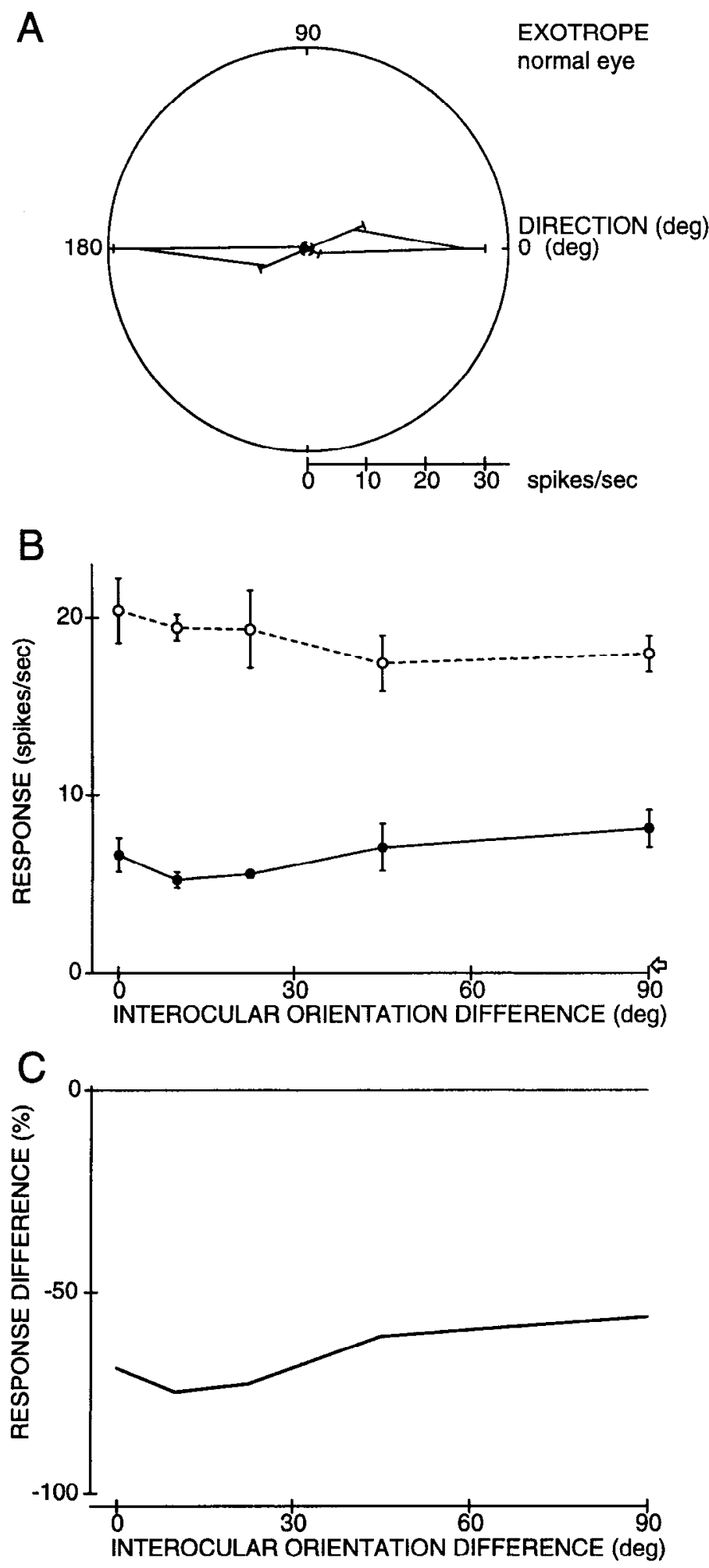

Figure 7. Orientation-independent interocular suppression in a layer $2 / 3$ simple cell from exotrope DS 1 , exclusively driven through the normal (ipsilateral) eye (OD group 7). $A$, Polar plot of orientation tuning curve for monocular stimulation through the dominant eye, with gratings of 0.7 contrast and a spatial frequency of $0.56 \mathrm{cycle} / \mathrm{degree}(n=$ 5 ). $B$, Result of the binocular interaction protocol, as in Figure $5 B$. A drifting "conditioning" grating of optimal orientation (direction $=180^{\circ}$; spatial frequency $=0.56$ cycle/degree; contrast $=0.35$ ) was presented continuously to the dominant, ipsilateral eye and gratings of various orientations (same spatial frequency, contrast $=0.7$ ) were shown intermittently to the contralateral eye $(n=8)$. $C$, Binocular interaction func- imals, for all cells that showed clear interocular suppression except one (see below), the suppression was essentially independent of orientation, whichever eye dominated the cell. This was also true in the esotropes for cells dominated by the nonsquinting eye. In one of the three esotropic animals (CS2, with a very large squint), this nonselective suppression was also seen in cells dominated by the deviating eye. In another esotrope, CS3, none of only three cells tested that were dominated by the deviating eye showed any significant binocular interaction. In the third esotrope (CS1, with a small-angle squint) just one of six apparently monocular cells that were dominated by the operated eye displayed interocular suppression but only for gratings of orthogonal or near-orthogonal orientation in the nonoperated eye.

\section{Selective iso-orientational binocular suppression}

In contrast to the prevailing nonselective suppression, just two units displayed clear interocular suppression only when the orientation of the grating presented to the nondominant eye was similar to the optimal orientation of the "conditioning" stimulus in the dominant eye and not at all when it was orthogonal. This selective iso-orientational suppression was again independent of relative interocular phase (disparity). One of these cells was a simple cell dominated by the deviating eye in the large-angle exotrope, DS1; the other was a complex cell dominated by the nonoperated eye in the large-angle esotrope, CS2 (see Fig. 11).

\section{Influence of spatial phase and spatial frequency on suppression}

We tested all cells that were significantly suppressed by isooriented gratings to see whether this effect was dependent on the relative spatial phase between the two eyes; in no case was there significant modulation of the depth of suppression with interocular phase (Fig. 12). This held for both complex and simple cells.

In 28 cells with clear interocular suppression, we further determined the spatial-frequency tuning of the suppressive signal. With the "conditioning" grating presented to the dominant eye always at the optimal spatial frequency, we presented drifting gratings of the same orientation to the other eye and varied the spatial frequency in pseudorandom sequence across presentations. The strongest suppression was invariably produced by gratings of spatial frequency similar to the optimum for excitation in the dominant eye (Fig. 13). However, in most cells, suppression was elicited over a range of spatial frequencies broader than the spatial-frequency tuning for excitation, and never over a narrower range (see Fig. 13). Gratings of \pm 1 octave around the optimum spatial frequency caused roughly equal suppression in 17 of the 28 cells tested. Figure 13 shows the spatial frequency tuning of suppression for the simple cell illustrated in Figures 7 and 12. This unit, like several others tested, was strongly suppressed by gratings of a spatial frequency too high to elicit a significant response in the dominant eye alone.

\section{Time course of suppression}

To judge the latency of onset and consistency over time of interocular suppression, we examined accumulated peristimulus time histograms (PSTHs) during the sudden introduction of a

tion, plotting the response difference (see Fig. $6 C$ ) as a function of the interocular difference in orientation. 
A
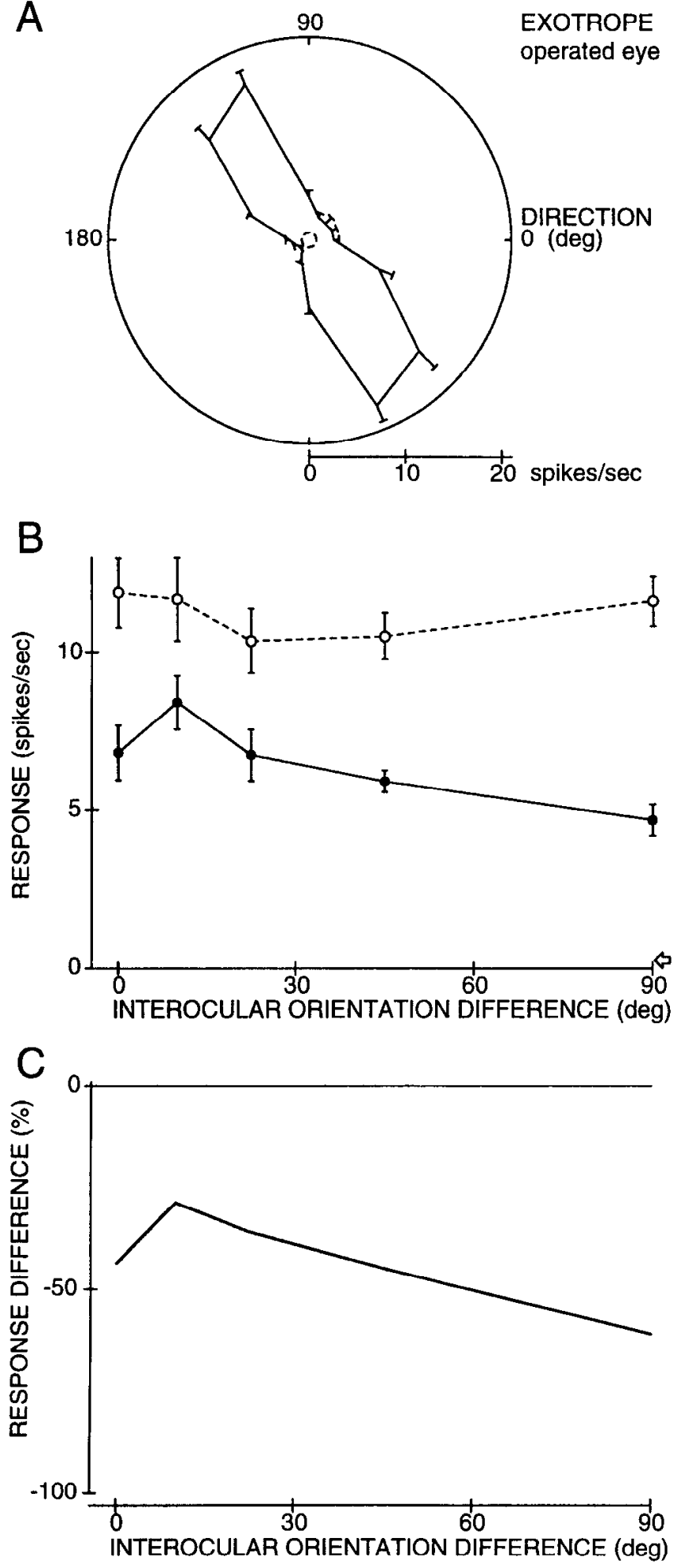

Figure 8. Orientation-independent interocular suppression in a layer $2 / 3$ simple cell from exotrope DS2, strongly dominated by the operated (contralateral) eye (OD group 2). $A$, Polar plot of orientation tuning curve for monocular, stimulation through the dominant eye, with gratings of 0.7 contrast and a spatial frequency of 0.8 cycle/degree $(n=5)$. The dashed circle in the center indicates the mean level of spontaneous discharge. $B$, Result of the binocular interaction protocol, as in Figure $5 B$. A drifting "conditioning" grating of optimal orientation (direction $=292.5$; spatial frequency $=0.8$ cycle $/$ degree; contrast $=0.35$ ) was presented continuously to the dominant, contralateral eye and gratings of various orientations (same spatial frequency, contrast $=0.7$ ) were suppressive, iso-oriented grating to the silent (or nondominant) eye, while the cell was responding to a "conditioning" stimulus in the other eye. For most of the 29 cells studied, suppression commenced quite sharply, 100-200 msec after the onset of binocular stimulation, and built up in strength over about $200 \mathrm{msec}$ thereafter (see Fig. 3C); however, for six cells, the latency of onset of suppression was as long as 400-800 msec (Fig. 3D,E). Suppression was generally strongest in the first second after the onset, followed by a slight recovery, but was always sustained at a significant tonic level throughout the $5 \mathrm{sec}$ period tested (Fig. 3C-E).

\section{Discussion}

In normal cats, most binocular neurons show distinct binocular summation, and often facilitation, when both eyes are stimulated at the appropriate retinal disparity (e.g., Barlow et al., 1967; Nikara et al., 1968; Freeman and Ohzawa, 1986), as long as the stimuli are roughly matched in orientation (Blakemore et al., 1972; Nelson et al., 1977). Even the majority of apparently monocular cells (except in layer 4 itself; Sengpiel et al., 1994) receive subliminal excitatory input from the silent eye, which can be revealed by the effects of binocular stimulation (Kato et al., 1981). Previous studies (Cynader et al., 1984; Xue et al., 1987) have shown that such binocular interactions are reduced or absent for monocular cells in strabismic cats. We, too, found only one monocular unit of 50 that showed any evidence of excitatory interaction during binocular stimulation, and that took the very unusual form of a transient facilitation at the onset of the stimulus in the silent eye (see Fig. $3 B$ ).

On the other hand, our results establish that the majority of apparently monocular neurons in strabismic animals do receive significant input from the silent eye, but its net effect is powerfully inhibitory. Moreover, by contrast with binocular interactions in normal cats (Blakemore et al., 1972; Nelson et al., 1977; Sengpiel et al., 1992, 1994), the interactions in strabismic cats are largely independent of the orientation and relative spatial phase of the stimulus presented to the nondominant eye. Suppression with iso-oriented gratings, independent of spatial phase, similar to the interactions we saw, was also seen by Freeman and Ohzawa (1988) in a small proportion of apparently monocular cells in monocularly deprived cats.

Just 5 of the 85 cells studied in strabismic animals showed iso-orientational facilitation and cross-orientational suppression (see Fig. 5) similar to that seen in the majority of cells in normal cats (Sengpiel et al., 1992, 1994). However, none of these cells exhibited normal disparity selectivity, and even among the 35 binocular cells tested, $28(80 \%)$ showed no evidence of binocular summation. There were no obvious differences between esotropic and exotropic, or between alternating and nonalternating animals in the fraction of cells showing binocular summation. Together, these findings might well account for the failure of binocular summation at threshold or subthreshold contrast levels in strabismic humans (Levi et al., 1979), as well as the loss of stereopsis and the lack of interocular transfer of visual aftereffects in most strabismic patients (e.g., Movshon et al., 1972; Ware and Mitchell, 1974; Mitchell et al., 1975). It is

shown intermittently to the ipsilateral eye $(n=7) . C$, Binocular interaction function, plotting the response difference (see Fig. $6 \mathrm{C}$ ) as a function of the interocular difference in orientation. 

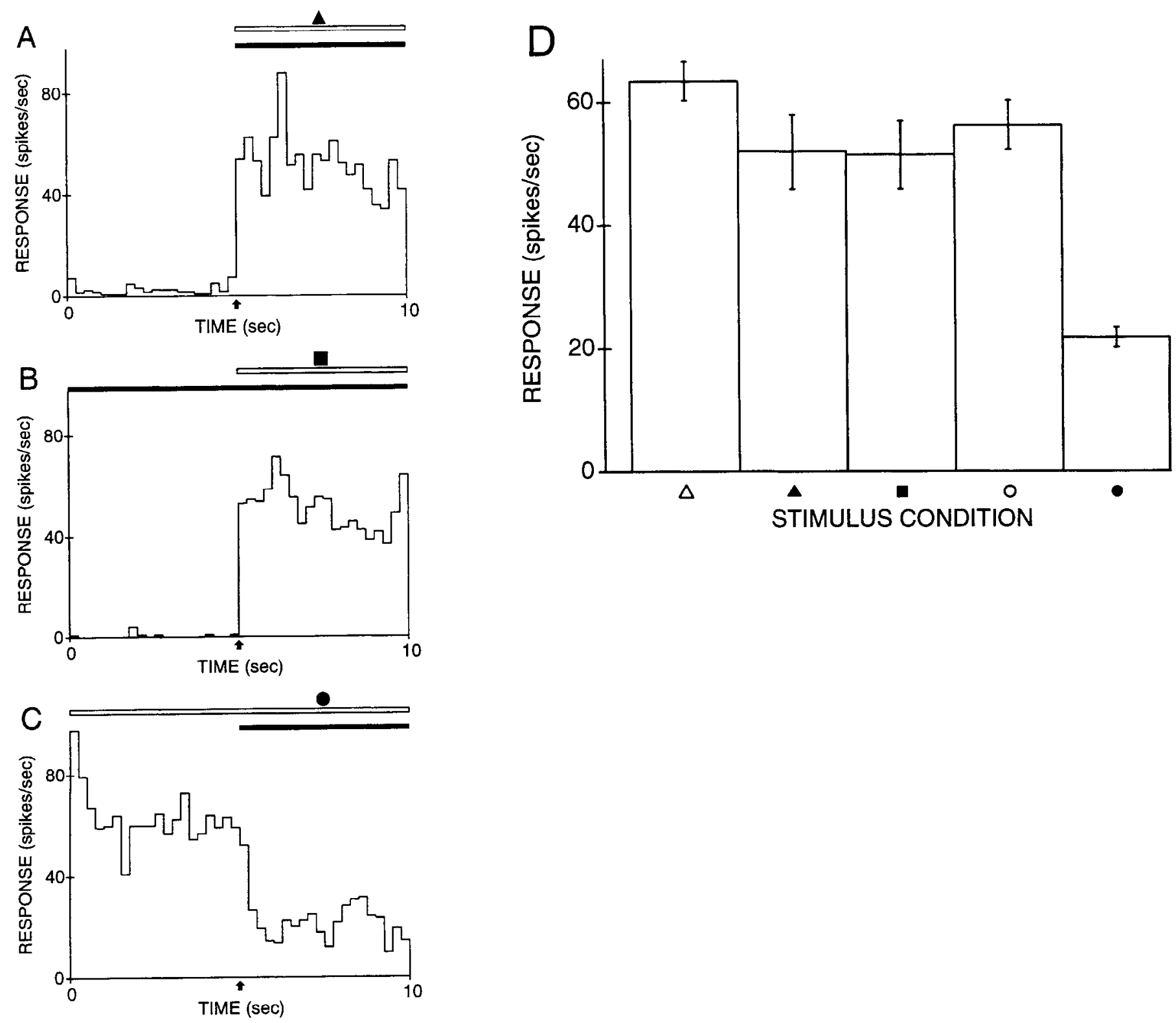

Figure 9. Dependence of response on the temporal sequence of stimulation for the monocularly driven layer $2 / 3$ complex cell shown in Figures $3, D$ and $E$, and 6 . Three experimental conditions were tested, in each of which drifting gratings ( 0.7 contrast) of identical orientation, optimum for the dominant eye, were simultaneously presented to both eyes during the second half of a 10 sec period. The only difference between these three conditions was the nature of stimulation during the $5 \mathrm{sec}$ period immediately preceding this binocular exposurc. Solid triangle, Condition A: blank screen presented to both eyes for the first $5 \mathrm{sec}$, with simultaneous onset in the two eyes at the start of the period of binocular stimulation. Solid square, Condition B: grating presented alone to the silent eye with the dominant eye viewing a blank screen for the first 5 sec. Solid circle, Condition C: optimal grating presented alone to the dominant eye during the initial $5 \mathrm{sec} . A-C$, PSTHs (each the average of five 10 sec presentations; bin width, $250 \mathrm{msec}$ ) of responses in the three experimental conditions A, B, and C above. The solid and open bars above each PSTH indicate the periods of stimulation of the silent and the dominant eye, respectively. When the stimulus appears in the silent eye (arrow) while the cell is already responding through the dominant eye $(C)$, there is strong suppression during the period of binocular stimulation. $D$, Histogram comparing responses (mean $\pm \mathrm{SEM}, n=5$ ) under the three experimental conditions A, B, and C described above and two further controls: open triangle, conditon I: the dominant eye alone was stimulated for the second $5 \mathrm{sec}$, preceded by $5 \mathrm{sec}$ of presentation of a blank screen of the same mean luminance. open circle, Condition II: the dominant eye was stimulated for the entire $10 \mathrm{sec}$ period and the response was measured during the latter 5 sec of each presentation, in order to control for adaptation or "fatigue" under experimental condition C above. In both cases, the nondominant eye viewed a blank screen. Only when the cell was already responding, because of prior presentation of the optimal grating to the dominant eye, did the grating in the other eye cause consistent suppression.

worth noting that some strabismic observers do exhibit residual binocular interactions (Hess, 1978; Anderson et al., 1980); such capacities may depend on the proportion of cortical cells still showing positive binocular interaction.

\section{Site and nature of interocular suppression}

The neural origin of the profound interocular suppression experienced by strabismic observers has been a matter of specu- 

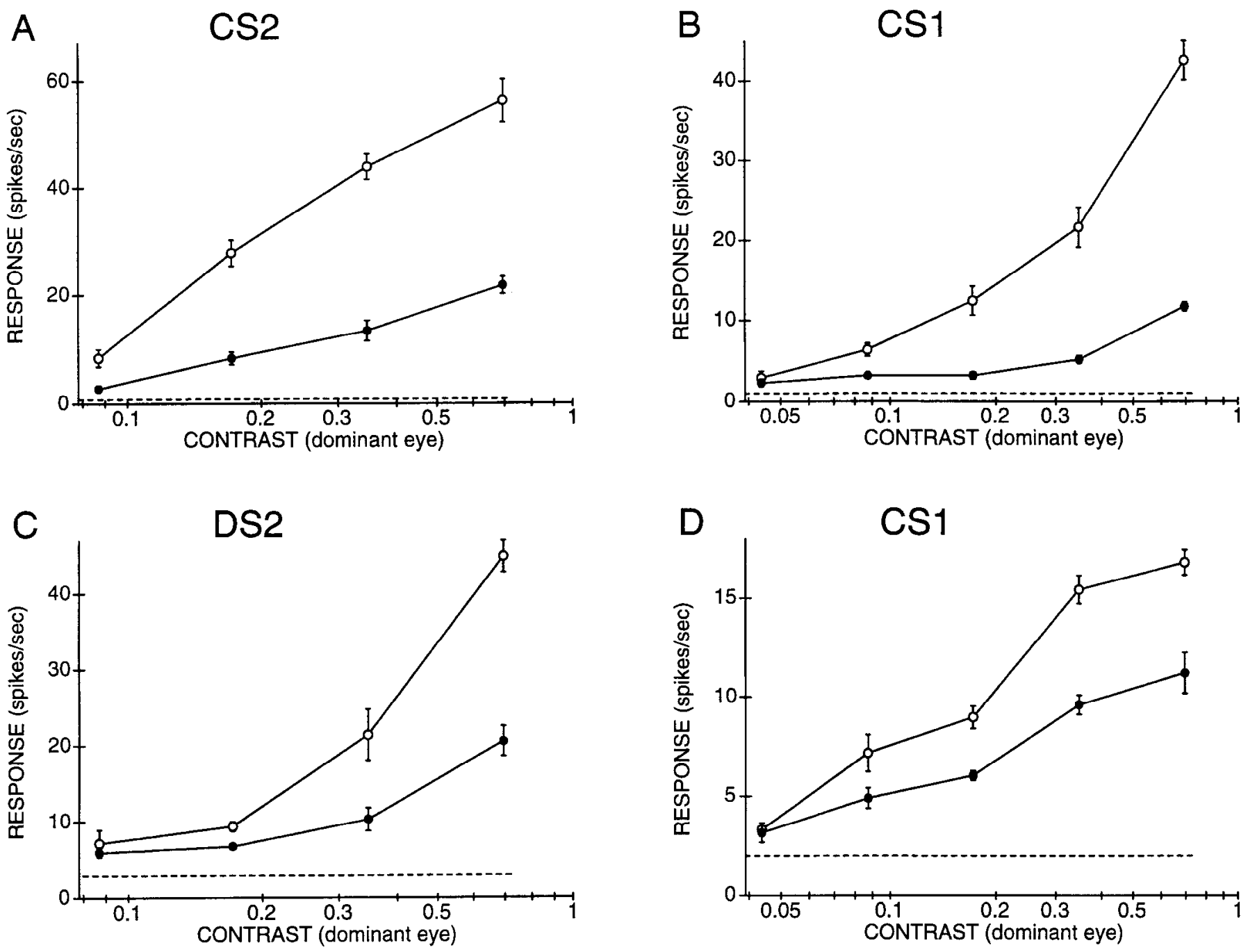

Figure 10. Contrast-response functions for experimental condition $\mathrm{C}$, in which binocular stimulation is preceded by presentation of an optimal grating to the dominant eye (solid circles), and the corresponding control condition II (open circles; see Fig. 9 legend) are shown for all four cells that were fully tested. The contrast of the grating shown to the dominant (nondeviating) eye was pseudorandomly varied in an interleaved series under each condition to provide the data for these functions. Mean responses in spikes/sec ( $\pm \mathrm{SEM}$; for $A, n=5$ presentations per data point; for $B-D, n=6$ ) are plotted against the contrast of the optimally oriented drifting grating shown to the dominant eye (the nondeviating eye for all four cells). The dashed lines indicate the mean level of spontaneous discharge measured during blank presentations with no pattern presented to either eye. $A$ depicts responses from the monocularly driven complex cell of Figure 9 . $B$ and $D$ show results from two apparently monocular simple cells recorded from the small-angle esotrope CS1. Contrast-response functions in $C$ were obtained from a complex cell that was dominated by the nonoperated eye but clearly responded to stimulation of the operated eye alone, in the alternator DS2.

lation for some time (e.g., Blake and Lehmkuhle, 1976; Hess, 1991). Psychophysical investigations have utilized the phenomenon of perceptual adaptation caused by prolonged exposure to high-contrast gratings (Blakemore and Campbell, 1969), which is, because of its orientation-dependence, thought to depend on neural effects in the visual cortex. Blake and Lehmkuhle (1976) reported that a grating presented to one eye of a strabismic alternator causes adaptation, that is, results in an elevation of contrast threshold, even if the eye viewing it is perceptually suppressed at the time. If the site of suppression were at or prior to that of the neural change underlying adaptation, any aftereffect should be diminished or absent. Blake and Lehmkuhle (1976) concluded that suppression occurs after the site of grating adaptation, which is assumed to be the primary visual cortex. In contrast, Hess (1991) found that strabismic amblyopes, who show grating adaptation when viewing monocularly with their amblyopic eyes, do not exhibit threshold elevation through the amblyopic eye after adapting under binocular viewing conditions. Hess's data suggest that, at least for strabismic amblyopes, suppression takes place at the site of adaptation, probably in V1. Physiological data presented here provide strong support for the notion that the primary visual cortex is indeed the site of interocular suppression in strabismus. Our results suggest no difference in that respect between alternating and unilaterally fixating animals, or between exotropes and esotropes. The suppressive interactions seen at the neuronal level clearly resemble pathological suppression in strabismic humans in their relative independence of stimulus parameters, in particular the virtual absence of selectivity for orientation (see Holopigian et al., 1988).

Inhibitory interocular interactions that are independent of relative orientation are seen in the lateral geniculate nucleus (LGN) of normal animals (Moore et al., 1992; Sengpiel et al., 


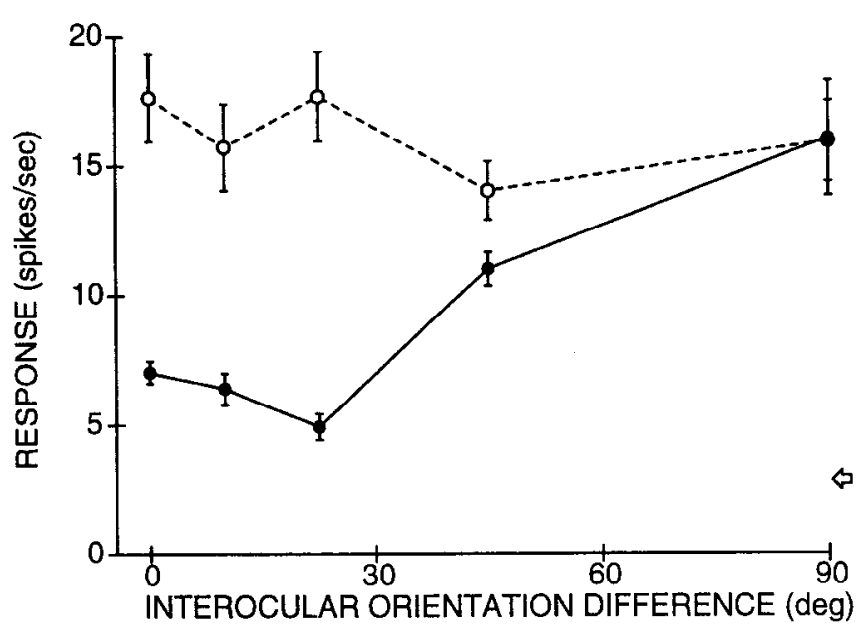

Figure 11. Orientation dependence of interocular suppression in a layer $2 / 3$ complex cell from esotrope CS2. This cell was strongly dominated by the operated eye (OD group 2). Results of the binocular interaction protocol are shown, as in Figure $5 B$. A drifting "conditioning" grating of optimal orientation (direction $=202.5^{\circ}$; spatial frequency $=$ 0.56 cycle/degree; contrast $=0.35$ ) was presented continuously to the dominant, contralateral eye and gratings of various orientations (same spatial frequency, contrast $=0.7$ ) were shown intermittently to the ipsilateral eye $(n=8)$. In this cell, suppression operated only at relatively small interocular orientation differences.

1992, 1994). One might then argue that the interocular suppression seen in the cortex of strabismic animals is simply due to the loss of excitatory binocular interactions in the cortex itself, revealing nonspecific interactions actually taking place in the LGN. For several reasons we believe that this is not the case. For one thing, interactions at the subcortical level are usually much weaker than those seen in the cortex. Second, interocular

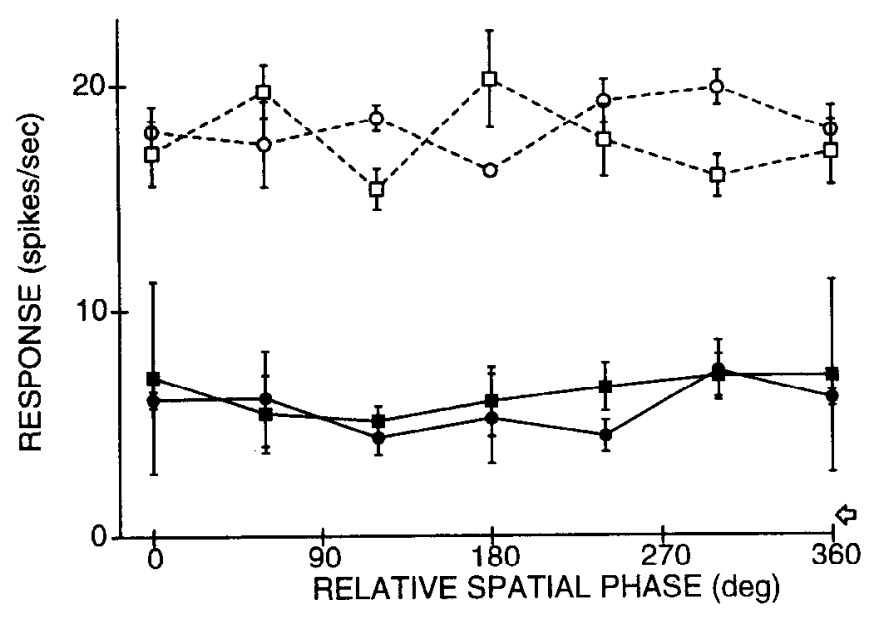

Figure 12. Binocular responses of the simple cell shown in Figure 7 as a function of the spatial phase of the grating in the silent (deviated) eye relative to that of the stimulus in the dominant eye. The triggering point of the optimally oriented drifting grating presented to the dominant eye (contrast $=0.35$; spatial frequency $=0.56 \mathrm{cycle} /$ degree) was fixed at an arbitrary value, while that of the grating presented to the other eye was varied in phase from presentation to presentation. The relative spatial phase between the two gratings is plotted on the abscissa. Solid circles show the results for iso-oriented gratings, while the open circles plot the control values during preceding periods of monocular stimulation. Solid and open squares plot comparable data for orthogonally oriented gratings. Note that even for iso-oriented gratings suppression was independent of relative interocular phase.
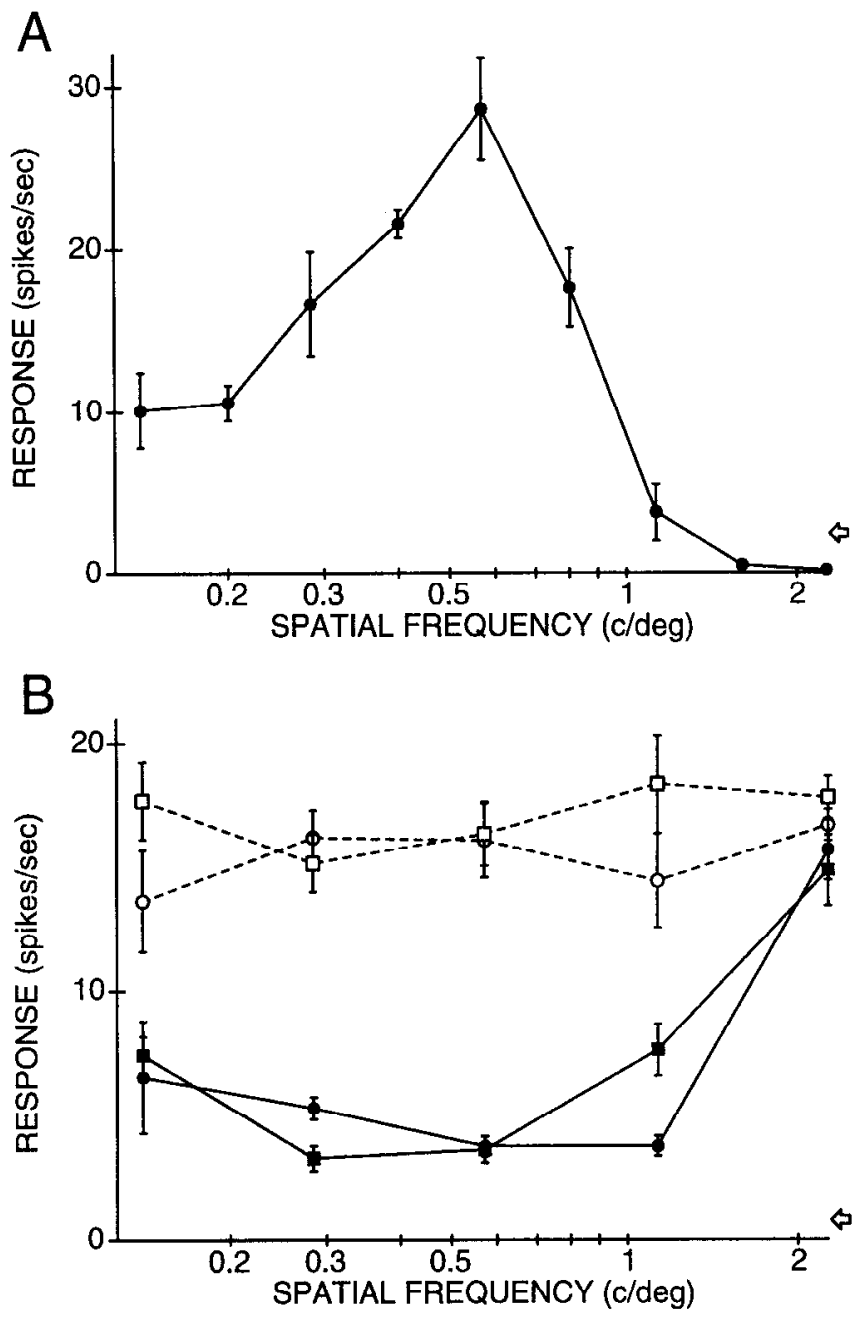

Figure 13. Spatial frequency dependence of suppression in a layer $2 / 3$ simple cell (same cell as for Figs. 7 and 12). $A$, Spatial frequency tuning of monocular responses obtained through the dominant (normal) eye (solid circles; \pm 1 SEM, $n=5$ ). The arrow indicates the spontaneous discharge. $B$, Binocular responses as a function of the spatial frequency of the grating in the silent (deviated) eye. The dominant eye was continuously stimulated with an optimally oriented grating of optimal spatial frequency $(0.56 \mathrm{cycle} / \mathrm{degree})$, while the nondominant eye was intermittently stimulated with gratings whose spatial frequency varied in pseudorandom sequence. Solid circles show the results for iso-oriented gratings, while the open circles plot the control values during preceding periods of monocular stimulation $(n=6)$. Solid and open squares plot comparable data for orthogonally oriented gratings $(n=6)$.

suppression in the LGN, unlike that in the cortex, does not appear to depend on the temporal sequence of stimulus presentation: it occurs with simultancous onset of stimulation in the two eyes (Moore et al., 1992) as well as during binocular stimulation following stimulation of the dominant eye alone (Sengpiel et al., 1992, 1994). Third, the occasional occurrence of orientation-dependent interocular suppression (see Fig. 11) could be explained by these inhibitory inputs deriving from oriented cortical units; the interaction might then be nonselective in most cells in strabismic animals because of convergence of inputs tuned to different orientations. Finally, interocular suppression in the cortex of strabismic cats is clearly less prominent in layer 4 , which receives the main geniculate input, than in supra- and infragranular layers (where it reached significance for two-thirds of all cells studied). 
Given current knowledge of the microcircuitry of the primary visual cortex (see Douglas et al., 1989; Douglas and Martin, 1991; Nicoll and Blakemore, 1993), it seems likely that intracortical inhibitory connections, mainly within cortical layers $2 / 3$, form the substrate for interocular suppression in strabismus, which is then fed down to infragranular layers. However, there is also the possibility that suppressive effects observed in area 17 are partly due to feedback inhibition from extrastriate visual cortical areas, especially when the latencies of onset of suppression are unusually long (see Fig. $3 C, D$ ).

In view of the fact that suppression in strabismic cats is largely independent of the orientation and spatial phase of the suppressive stimulus and occurs for a wide range of spatial frequencies, the inhibitory inputs responsible are likely to derive from a pool of cells with somewhat scattered receptive fields and a wide range of preferred orientations and spatial frequencies. It is tempting to speculate that the suppressive mechanism is based upon reciprocal inhibitory connections between neighboring OD columns dominated by the right and left eyes. At first thought, this hypothesis seems to be at odds with a recent anatomical study showing that intrinsic horizontal connections between OD columns are selectively lost in V1 of strabismic kittens: following cortical injections of fluorescent beads into one OD column, clusters of retrogradely labeled cells were predominantly found in territories activated by the same eye (Löwel and Singer, 1992; see also Tychsen and Burkhalter, 1992, for a similar finding in the monkey). However, these clusters of cells probably mainly indicate regions sending excitatory projections to the injection site, since inhibitory connections form only a small fraction of all intrinsic projections in V1 (see Kisvárday et al., 1986) and they are more uniform in their distribution (Somogyi et al., 1983; Albus et al., 1991). It is therefore conceivable that the reduction in horizontal connectivity between columns of opposite eye dominance observed in strabismic animals is due to a selective loss of excitatory but not inhibitory connections (see Levi et al., 1979). This notion receives further support from the finding that synchronization of neuronal responses in V1 of strabismic cats is reduced between cells dominated by different eyes, again reflecting a lack of long-range excitatory interactions (König et al., 1993).

\section{Contrast gain control and alternation of suppression}

Interocular suppression in the cortex of strabismic cats exhibits a gross nonlinearity in that it depends critically on the immediate history of visual stimulation (Sengpiel and Blakemore, 1994; see also Fig. 9). A neuron is switched into the suppressed mode only when the monocular suppressive stimulus appears while the cell is already being activated through the other eye. To some extent, there is a perceptual parallel of this nonlinearity in that perceptual suppression also does not occur when stimuli are briefly presented simultaneously to the two eyes of strabismic amblyopes: both are seen, "falsely fused" (Wolfe, 1986). Moreover, our data suggest that the percentage suppression of response is largely independent of the contrast of the suppressed stimulus (see Fig. 10). This suggests that, if suppression results from interocular inhibition, then inhibition may be divisive rather than subtractive, in contrast with reductions in the response to a grating caused by the addition of an iso-oriented "masking" grating in the same eye, which are characterized by an elevation of threshold contrast and a rightward shift of the contrast gain function without a change in slope (Morrone et al., 1987).
The interocular control of contrast gain in strabismic suppression clearly resembles that seen in normal cat cortex (Sengpiel and Blakemore, 1993, 1994). Since the majority of excitatory synapses on neurons in area 17 derive from closely neighboring cells rather than from thalamic afferents (Kisvárday et al., 1986; Douglas and Martin, 1991) the responsiveness of cortical neurons is likely to depend crucially on "amplification" performed by local excitatory circuitry within the same OD column (Douglas et al., 1989; Nicoll and Blakemore, 1993). The intrinsic excitatory circuitry mediating this local amplification may indeed be unaffected by squint (Löwel and Singer, 1992; König et al., 1993). Perhaps surviving inhibitory connections between adjacent OD columns modulate the gain of this local intrinsic excitation. The very long latencies of suppression observed for some neurons in this study (Fig. $3 D, E$ ) may reflect a slow buildup in the attenuation of the excitatory amplifier. The alternations in eye dominance experienced by many strabismic subjects (those without deep amblyopia) might either be triggered by visual stimuli appearing in the fovea of one eye, or occur spontaneously, possibly due to adaptation or fatigue of the inhibitory neurons responsible (Lehky, 1988). Such fatigue might also explain why interocular suppression is seen only with staggered but not with simultaneous binocular stimulus presentation: preliminary stimulation through one eye alone could cause fatigue of inhibitory interneurons in that eye's OD columns, so that when the other eye is subsequently stimulated, inhibition from its columns exceeds that in the reverse direction, leading to suppression.

\section{Suppression and amblyopia}

Recently, Harrad and Hess (1992a) found that strabismic suppression (determined as the elevation of contrast threshold in the amblyopic eye caused by a masking grating in the normal eye) is more powerful in strabismic amblyopia than in many cases of anisometropic amblyopia, suggesting that the relationship between suppression and amblyopia is not straightforward (cf. Schor, 1991). Harrad and Hess (1992b) proposed that the nature of suppression is different for different types of amblyopia, and that the depth of suppression is inversely related to the degree of binocularity, that is, the percentage of surviving binocular neurons (see Blake, 1989). This notion is supported by our finding that, in strabismic cats, striate neurons with more or less balanced inputs from the two eyes show binocular interactions closest to normal (Sengpiel et al., 1992, 1994) at least in terms of their orientation selectivity, whereas the majority of cells with weak or no direct input from one eye exhibit profound suppression.

Our results further suggest that neural suppression of either eye in alternators (like cat DS2) as well as of the fixating eye in nonalternating animals is of roughly the same strength, that is, not obviously dependent on angle of squint or state of fixation. However, contrary to what one might expect, no suppression was seen among cells dominated by the deviating eye in two convergent strabismic cats. In one cat (CS3), the small number of cells studied does not allow any firm conclusions. The other (CS1) was characterized by small-angle esotropia, an apparent shift in OD toward the nonoperated (fixating) eye, and perhaps even a slight neural acuity deficit in the deviating eye. This animal seemed the most likely among the cats included in this study to have developed amblyopia in the central part of the visual field of the deviating eye. The finding that, in this animal, cells with receptive fields in the area centralis of the deviating 
eye were not suppressed by stimuli in the other eye is reminiscent of the inverse correlation between the strengths of amblyopia and suppression in strabismic humans (Holopigian et al., 1988). Suppression appears to decrease once deep amblyopia is established, as if there were no longer a "need" for strong suppression of the amblyopic eye to eliminate double vision. The relationship between the degree of interocular suppression and the angle of squint, mobility of the eye, and presence of amblyopia deserves further examination.

\section{Suppression in strabismus and in binocular rivalry}

Apart from the fact that interocular suppression in the cortex of strabismic cats is usually independent of relative orientation, it is remarkably similar in its characteristics to the suppression produced by binocular gratings of differing orientation in normal cat cortex (Sengpiel et al., 1992, 1994). Both phenomena show broad spatial frequency tuning and are independent of relative spatial phase (even for iso-oriented binocular stimuli in the case of strabismic animals). Strabismic suppression and rivalrous suppression are of roughly equal strength (about $50 \%$ of monocular responses). Finally, and most importantly, both phenomena exhibit the same dynamics of interocular gain control. These similarities suggest that, even in normal animals, suppression is essentially nonselective for orientation but is swamped by powerful facilitation for matching stimuli.

Our results strongly support the view that the neural mechanisms underpinning suppression in binocular rivalry and strabismus, respectively, are similar if not identical. Psychophysical investigations have also revealed similarities between rivalry and strabismic suppression. Most notably, the two phenomena build up with similar "rise times" after an initial period of perceptual fusion (Wolfe, 1986). Moreover, if stimuli in the two eyes of a strabismic amblyope are made equally visible by attenuating the stimulus in the dominant eye, alternating suppression occurs, similar to binocular rivalry in normal subjects (Leonards and Sireteanu, 1993). However, threshold elevation in strabismic suppression (although varying among subjects) is usually much greater than in binocular rivalry (Holopigian et al., 1988). Also, rivalry suppression is more affected by interocular spatial frequency differences than is strabismic suppression (Schor, 1977) and appears more strongly to reduce the visibility of short-wavelength stimuli (Smith et al., 1985). It is conceivable that these differences between the two phenomena reflect minor modifications of the underlying neural network. The greater depth of suppression in strabismics may, for instance, simply be due to a higher number of cells involved in reciprocal inhibition rather than to a fundamental difference in the neural mechanism itself (see Blake, 1989). On balance, there is reason to believe that the pathological suppression associated with strabismus evolves from the same neural circuitry that produces alternating suppression in normal binocular rivalry, and that both are due to inhibitory interaction between $O D$ columns in the striate cortex.

\section{References}

Albus K, Wahle P, Lübke J, Matute C (1991) The contribution of GABA-ergic neurons to horizontal intrinsic connections in upper layers of the cat's striate cortex. Exp Brain Res 85:235-239.

Anderson P, Mitchell DE, Timney B (1980) Residual binocular interaction in stereoblind humans. Vision Res 20:603-611.

Barlow HB, Blakemore C, Pettigrew JD (1967) The neural mechanism of binocular depth discrimination. J Physiol (Lond) 193:327-342.
Blake R (1989) A neural theory of binocular rivalry. Psychol Rev 96: 145-167.

Blake R, Lehmkuhle SW (1976) On the site of strabismic suppression. Invest Ophthalmol 15:660-663.

Blakemore $C$ (1976) The conditions required for the maintenance of binocularity in the kitten's visual cortex. J Physiol (Lond) 261:423444.

Blakemore C, Campbell FW (1969) On the existence of neurones in the human visual system selectively sensitive to the orientation and size of retinal images. J Physiol (Lond) 203:237-260.

Blakemore C, Price DJ (1987) The organization and postnatal development of area 18 of the cat's visual cortex. J Physiol (Lond) 384: 263-292.

Blakemore C, Fiorentini F, Maffei L (1972) A second mechanism of binocular depth discrimination. J Physiol (Lond) 226:725-749.

Chino YM, Shansky MS, Jankowski WL, Banser FA (1983) Effects of rearing kittens with convergent strabismus on development of receptive-field properties in striate cortex neurons. J Neurophysiol 50:265286.

Crewther DP, Crewther SG (1990) Neural site of strabismic amblyopia in cats: spatial frequency deficit in primary cortical neurons. Exp Brain Res 79:615-622.

Crewther SG, Crewther DP (1993) Amblyopia and suppression in binocular cortical neurones of strabismic cat. Neuroreport 4:10831086.

Cynader M, Gardner JC, Mustari M (1984) Effects of neonatally induced strabismus on binocular responses in cat area 18. Exp Brain Res 53:384-399.

Douglas RJ, Martin KAC (1991) A functional microcircuit for cat visual cortex. J Physiol (Lond) 440:735-769.

Douglas RJ, Martin KAC, Whitteridge D (1989) A canonical microcircuit for neocortex. Neural Comput 1:480-488.

Duke-Elder SH (1973) System of ophthalmology, Vol VI, Ocular motility and strabismus (Duke-Elder S, Wybar K, eds), pp 251-256. London: Kimpton.

Dürsteler MR, von der Heydt R (1983) Plasticity in the binocular correspondence of striate cortical receptive fields in kittens. J Physiol (Lond) 345:87-105.

Freeman RD, Ohzawa I (1988) Monocularly deprived cats: binocular tests of cortical cells reveal functional connections from the deprived eye. J Neurosci 8:2491-2506.

Freeman RD, Tsumoto T (1983) An electrophysiological comparison of convergent and divergent strabismus in the cat: electrical and visual activation of single cortical cells. J Neurophysiol 49:238-253.

Harrad RA, Hess RF (1992a) Binocular integration of contrast information in amblyopia. Vision Res 32:2135-2150.

Harrad RA, Hess RF (1992b) A model for suppression in amblyopia. In: Transactions of the 20th meeting of the European Strabismological Association (Kaufmann H, ed), pp 113-118.

Henry GH, Dreher B, Bishop PO (1974) Orientation specificity of cells in cat striate cortex. J Neurophysiol 37:1394-1409.

Hess RF (1978) Interocular transfer in individuals with strabismic amblyopia; a cautionary note. Perception 7:201-205.

Hess RF (1991) The site and nature of suppression in squint amblyopia. Vision Res 31:111-117.

Holopigian K, Blake R, Greenwald MJ (1988) Clinical suppression and amblyopia. Invest Ophthalmol Vis Sci 29:444-451.

Iubel DH, Wiesel TN (1962) Receptive fields, binocular interaction and functional architecture in the cat's visual cortex. J Physiol (Lond) 160:106-154.

Hubel DH, Wiesel TN (1965) Binocular interaction in striate cortex of kittens reared with artificial squint. J Neurophysiol 28:1041-1059.

Kalil RE, Spear PD, Langsetmo A (1984) Response properties of striate cortex neurons in cats raised with divergent or convergent strabismus. J Neurophysiol 52:514-537.

Kato H, Bishop PO, Orban GA (1981) Binocular interaction on monocularly discharged lateral geniculate and striate neurons in the cat. J Neurophysiol 46:932-951.

Kiorpes L, Boothe RG (1981) Naturally occurring strabismus in monkey (Macaca nemestrina). Invest Ophthalmol Vis Sci 20:257-263.

Kisvárday ZF, Martin KAC, Freund TF, Maglóczky Z, Whitteridge D, Somogyi P (1986) Synaptic targets of HRP-filled layer III pyramidal cells in the cat striate cortex. Exp Brain Res 64:541-552.

König P, Engel AK, Löwel S, Singer W (1993) Squint affects synchronization of oscillatory responses in cat visual system. Eur J Neurosci 5:501-508. 
Lehky SR (1988) An astable multivibrator model of binocular rivalry. Perception 17:215-228.

Lema S, Blake R (1977) Binocular summation in normal and stereoblind humans. Vision Res 17:691-695.

Leonards U, Sireteanu R (1993) Interocular suppression in normal and amblyopic subjects: the effect of unilateral attenuation with neutral density filters. Percept Psychophysiol 54:65-74.

Levi DM, Harwerth RS, Smith EL III (1979) Humans deprived of normal binocular vision have binocular interactions tuned to size and orientation. Science 206:852-854.

Löwel S, Singer W (1992) Selection of intrinsic horizontal connections in the visual cortex by correlated neuronal activity. Science 255:209212.

Mitchell DE (1988) Animal models of human strabismic amblyopia: some observations concerning the interpretation of the effects of surgically and optically induced strabismus in cats and monkeys. In: Advances in neural and behavioral development, Vol 3 (Shinkman PG, ed), pp 209-269. Norwood, NJ: Ablex.

Mitchell DE, Reardon J, Muir DW (1975) Interocular transfer of the motion after-effect in normal and stereoblind observers. Exp Brain Res 22:163-173.

Moore RJ, Spear PD, Kim CBY, Xue JT (1992) Binocular processing in the cat's dorsal lateral geniculate nucleus. III. Spatial frequency, orientation, and direction sensitivity of nondominant-eye influences. Exp Brain Res 89:588-598.

Morrone MC, Burr DC, Speed HD (1987) Cross-orientation inhibition in cat is GABA mediated. Exp Brain Res 67:635-644.

Movshon JA, Chambers BEI, Blakemore C (1972) Interocular transfer in normal humans and those who lack stereopsis. Perception 1:483490.

Mower GD, Burchfiel JL, Duffy FH (1982) Animal models of strabismic amblyopia: physiological studies of visual cortex and the lateral geniculate nucleus. Dev Brain Res 5:311-327.

Nelson JI, Kato H, Bishop PO (1977) Discrimination of orientation and position disparities by binocularly activated neurons in cat striate cortex. J Neurophysiol 40:260-283.

Nicoll A, Blakemore C (1993) Patterns of local connectivity in the neocortex. Neural Comput 5:665-680.

Nikara T, Bishop PO, Pettigrew JD (1968) Analysis of retinal correspondence by studying receptive fields of binocular single units in cat striate cortex. Exp Brain Res 6:353-372.

Ohzawa I, Freeman RD (1986a) The binocular organization of simple cells in the cat's visual cortex. J Neurophysiol 56:221-242.

Ohzawa I, Freeman RD (1986b) The binocular organization of complex cells in the cat's visual cortex. J Neurophysiol 56:243-259.

Rose D, Blakemore C (1974) An analysis of orientation selectivity in the cat's visual cortex. Exp Brain Res 20:1-17.

Schor CM (1977) Visual stimuli for strabismic suppression. Perception 6:583-593.

Schor CM (1991) Binocular sensory disorders. In: Vision and visual dysfunction, Vol 9, Binocular vision (Regan D, ed), pp 179-223. London: Macmillan.

Sclar G, Ohzawa I, Freeman RD (1986) Binocular summation in normal, monocularly deprived, and strabismic cats: visual evoked potentials. Exp Brain Res 62:1-10.

Sengpiel F, Blakemore C (1993) Neurons in cat area 17 exhibit bistable response gain during binocular stimulation. Soc Neurosci Abstr 19: 628.

Sengpiel F, Blakemore C (1994) Interocular control of neuronal responsiveness in cat visual cortex. Nature $368: 847-850$.
Sengpiel F, Harrad RA, Blakemore C (1992) Responses of cells in the cat's LGN and area 17 to rivalrous stimuli. Soc Neurosci Abstr 18: 295.

Sengpiel F, Kind PC, Harrad RA, Blakemore C (1993) Interocular suppression in area 17 of strabismic cats. Invest Ophthalmol Vis Sci 34:1033.

Sengpiel F, Blakemore C, Harrad R (1994) Interocular suppression in the primary visual cortex: a possible neural basis of binocular rivalry. Vision Res, in press.

Shinkman PG, Bruce CJ (1977) Binocular differences in cortical receptive fields of kittens after rotationally disparate binocular experience. Science 197:285-287.

Shlaer R (1971) Shift in binocular disparity causes compensating change in the cortical structure of kittens. Science 173:638-641.

Singer W, Rauschecker J, von Grünau MW (1979) Squint affects striate cortex cells encoding horizontal image movements. Brain Res 170: 182-186.

Singer W, von Grünau MW, Rauschecker J (1980) Functional amblyopia in kittens with unilateral exotropia. I. Electrophysiological assessment. Exp Brain Res 40:294-304.

Sireteanu R (1982) Binocular vision in strabismic humans with alternating fixation. Vision Res 22:889-896.

Sireteanu R, Best J (1992) Squint-induced modification of visual receptive fields in the lateral suprasylvian cortex of the cat: binocular interaction, vertical effect and anomalous correspondence. Eur J Neurosci 4:235-242.

Sirctcanu R, Fronius M (1981) Naso-temporal asymmetrics in human amblyopia: consequence of long-term interocular suppression. Vision Res 21:1055-1063.

Smith EL, Levi DM, Manny RE, Harwerth RS, White JM (1985) The relationship between binocular rivalry and strabismic suppression. Invest Ophthalmol Vis Sci 26:80-87.

Somogyi P, Kisvárday ZF, Martin KAC, Whitteridge D (1983) Synaptic connections of morphologically identified and physiologically characterized large basket cells in the striate cortex of the cat. Neuroscience 10:261-294.

Tremain KE, Ikeda H (1982) Relationship between amblyopia, LGN cell "shrinkage" and cortical ocular dominance. Exp Brain Res 45: 243-252.

Tychsen L, Burkhalter A (1992) Naturally-strabismic primate lacks intrinsic horizontal connections for binocular vision in striate cortex. Soc Neurosci Abstr 18:1455.

Van Sluyters RC, Levitt FB (1980) Experimental strabismus in the kitten. J Neurophysiol 43:686-699.

von Grünau MW (1979) Binocular summation and the binocularity of cat visual cortex. Vision Res 19:813-816.

Ware C, Mitchell DE (1974) On interocular transfer of various visual aftereffects in normal and stereoblind observers. Vision Res 14:731734

Wolfe JM (1986) Briefly presented stimuli can disrupt constant suppression and binocular rivalry suppression. Perception 15:413-417.

Wörgötter F, Gründel O, Eysel UT (1990) Quantification and comparison of cell properties in cat's striate cortex determined by different types of stimuli. Eur J Neurosci 2:928-941.

Xue JT, Freeman RD, Carney T, Shadlen M (1987) Binocular interaction in strabismic cats. Invest Ophthalmol Vis Sci [Suppl] 28:102.

Yinon U, Auerbach E, Blank M, Friesenhausen J (1975) The ocular dominance of cortical neurons in cats developed with divergent and convergent squint. Vision Res 15:1251-1256. 